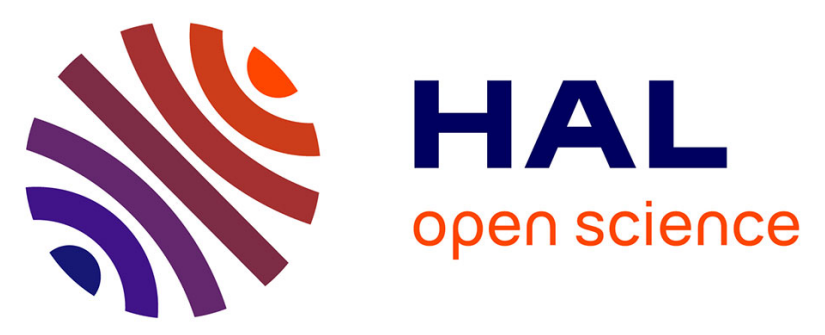

\title{
Validation of a near-body and off-body grid partitioning methodology for aircraft aerodynamic performance prediction
}

David Hue, Ludovic Wiart, Elie Gournay, Olivier Atinault, Stéphanie Péron, Pascal Raud, Christophe Benoit, Julien Mayeur

\section{To cite this version:}

David Hue, Ludovic Wiart, Elie Gournay, Olivier Atinault, Stéphanie Péron, et al.. Validation of a near-body and off-body grid partitioning methodology for aircraft aerodynamic performance prediction. Computers and Fluids, 2015, 117, pp.196-211. 10.1016/j.compfluid.2015.05.021 . hal-01229417

\section{HAL Id: hal-01229417 https://hal.science/hal-01229417}

Submitted on 16 Nov 2018

HAL is a multi-disciplinary open access archive for the deposit and dissemination of scientific research documents, whether they are published or not. The documents may come from teaching and research institutions in France or abroad, or from public or private research centers.
L'archive ouverte pluridisciplinaire HAL, est destinée au dépôt et à la diffusion de documents scientifiques de niveau recherche, publiés ou non, émanant des établissements d'enseignement et de recherche français ou étrangers, des laboratoires publics ou privés. 


\title{
Validation of a near-body and off-body grid partitioning methodology for aircraft aerodynamic performance prediction
}

\author{
David HUE ${ }^{1}$, Ludovic WIART ${ }^{2}$, Elie GOURNAY ${ }^{3}$, Olivier ATINAULT ${ }^{4}$, \\ Stéphanie PERON ${ }^{5}$, Pascal RAUD $^{6}$, Christophe BENOIT $^{7}$, and Julien MAYEUR ${ }^{8}$ \\ ONERA-The French Aerospace Lab, 92190 Meudon, France
}

This article describes a methodology based on overset grids that enables to simplify and shorten the mesh generation process for aircraft configurations. It is based on the keyconcept of partitioning the computational domain: the near-body areas are meshed by a set of body-fitted structured grids while the off-body domain is meshed by an automated octreebased Cartesian grid approach. This state-of-the-art combination allows to consider a complex configuration as the sum of simple elements such as fuselage, wing, winglets, tailplanes... As a consequence, the method exhibits several decisive advantages: easiness, flexibility, rapid implementation, Cartesian grid adaptation... In order to apply and validate the overall approach, a well-known configuration, the NASA Common Research Model, has been chosen. It is an open geometry representative of current wide-body commercial aircraft which has been used in the international Drag Prediction Workshops. In this paper, the complete building of two sets of overset grids is described. Then, for near-field and far-field drags as much as for local analyses, the results obtained with this new overset strategy are compared to the data produced by the common point-matched Drag Prediction Workshop grids and a very satisfactory agreement is observed. Moreover, some advantages of Cartesian grid adaptation are highlighted.

\footnotetext{
${ }^{1}$ Engineer, Civil Aircraft Unit, Applied Aerodynamics Department, david.hue@ onera.fr, Member AIAA.

${ }^{2}$ Engineer, Civil Aircraft Unit, Applied Aerodynamics Department, ludovic.wiart@ onera.fr, Member AIAA.

${ }^{3}$ Engineer (internship), Civil Aircraft Unit, Applied Aerodynamics Department.

${ }^{4}$ Engineer, Civil Aircraft Unit, Applied Aerodynamics Department, olivier.atinault@onera.fr.

${ }^{5}$ Engineer, CS2A Unit, CFD and Aeroacoustics Department, stephanie.peron@ onera.fr.

${ }^{6}$ Engineer, CS2A Unit, CFD and Aeroacoustics Department, pascal.raud@onera.fr.

${ }^{7}$ Engineer, CS2A Unit, CFD and Aeroacoustics Department, christophe.benoit@onera.fr.

${ }^{8}$ Engineer, CS2A Unit, CFD and Aeroacoustics Department, julien.mayeur@ onera.fr.
} 


\section{Nomenclature}

$$
\begin{aligned}
& \text { alpha = angle of attack } \\
& A R \quad=\text { aspect ratio } \\
& b \quad=\text { wing span } \\
& \text { c } \quad=\text { wing chord } \\
& C D f=\text { friction drag coefficient } \\
& C D f f \quad=\text { far-field drag coefficient } \\
& C D i=\text { lift-induced drag coefficient } \\
& C D n f=\text { near-field drag coefficient } \\
& C D p \quad=\text { pressure drag coefficient } \\
& C D s p=\text { spurious drag coefficient } \\
& C D v \quad=\text { viscous drag coefficient } \\
& C D v p=\text { viscous pressure drag coefficient } \\
& C D w=\text { wave drag coefficient } \\
& C f=\text { skin friction coefficient } \\
& C L=\text { lift coefficient } \\
& C M=\text { pitching moment coefficient } \\
& C p \quad=\text { pressure coefficient } \\
& \text { Ma = Mach number } \\
& \text { Re }=\text { Reynolds number } \\
& \text { Sref }=\text { reference surface area } \\
& u, v, w=X, Y, Z \text { velocity components } \\
& Y^{+} \quad=\text { normalized first cell height } \\
& \eta \quad=\text { fraction of wing span } \\
& \infty=\text { subscript for freestream state value }
\end{aligned}
$$




\section{Introduction}

OMPUTATIONAL Fluid Dynamics (CFD) has successfully grown over the past decades, in particular for aircraft design. Since Reynolds-averaged Navier-Stokes (RANS) simulations are nowadays performed within an acceptable time frame, configurations that are simulated tend to become more and more complex, involving bodies in relative motion or with geometrical details. Thus, the mesh generation process for industrial configurations still remains challenging; it is time-consuming and requires very specific skills.

For that matter, overset grid methods, also known as Chimera approaches [1], have been used for many years in the CFD community as a means to reduce the mesh generation effort, in particular for structured grids $[2,3]$. Then, Cartesian grids have been introduced within the overset grid framework in order to mesh the off-body domain, whereas near-body regions can be meshed by overlapping or abutting body-fitted grids extending to a short distance from body surfaces $[4,5,6,7]$. At ONERA, an octree-based Cartesian mesh generation and adaptation has been implemented in Cassiopée modules [8,9], enabling to adapt locally the Cartesian grid refinement to near-body grid density levels. Once the near-body and off-body domains are meshed, the overset grid assembly can be performed prior to the CFD solver using packages such as Pegasus [10], Pundit [11], Suggar++ [12], and Cassiopée [9], or within the CFD solver (Overflow [13], elsA [14,15]).

In the present paper, this near-body/off-body mesh partitioning of the computational volume is applied and each element of the aircraft configuration (fuselage, wing...) is meshed separately with the commercial software Pointwise [16]. Then, off-body adaptive Cartesian grids are generated using the octree approach available in the inhouse Cassiopée modules. Finally, overset grid assembly is achieved using the module Connector of Cassiopée, according to assembly rules between pairs of elements [17,18]. All these tools used together allow to generate satisfactory meshes and then to perform the necessary pre-processing within a short time frame. Furthermore, along the whole CFD procedure, from the meshing step to the computation post-processing, only the CGNS format is used, which clearly allows to simplify the user work.

Recently, several studies have been successfully carried out with this ONERA meshing method [19,20,21]. In order to demonstrate its capabilities in this article, the NASA Common Research Model (CRM) used in the latest Drag Prediction Workshops (DPW-4/5) has been chosen [22]. The CRM is an open geometry representative of 
current wide-body commercial aircraft [23], for which a wealth of experimental and numerical data is available. This configuration has been deeply studied at ONERA [24,25,26].

The paper is organized as follows: first, the CRM geometry is briefly described. Then, the reference grids and results from DPW-4 and DPW-5 will be presented; they will be used for comparison purposes. The near and Cartesian off-body grid method in itself will be explained and the associated grids will be shown. In a short section, the ONERA CFD software used for the RANS computations and post-processing will be described. Finally, the results obtained by this innovative meshing strategy will be analyzed and commented. Some numerical considerations involving multigrid techniques and grid adaptation will be addressed.

\section{The CRM as a Multi-Element configuration}

\section{A. CRM Geometry}

In the context of DPW-4 and DPW-5 studies, the CRM wing-body (WB) configuration has respectively been used either with a Horizontal Tail Plane (HTP) or without. This relevant geometry was designed by a NASA / Boeing Technical Working Group. As a result, the CRM has the following characteristics: conventional low-wing configuration, possible nacelle/pylon installation, design Mach number of 0.85 , fuselage representative of a wide/body commercial aircraft. The reference geometry is defined by mean-aerodynamic chord $c=7.00532 \mathrm{~m}$, reference surface area Sref $=383.68956 \mathrm{~m}^{2}$ (full-model), half-span $b / 2=29.38145 \mathrm{~m}$, aspect ratio $A R=9.0$, and moment center Xref $=33.67786 \mathrm{~m}$, Yref $=0.0 \mathrm{~m}$, and Zref $=4.51993 \mathrm{~m}$. In this study, the HTP setting is always $0^{\circ}$.

As mentioned in recent articles [27], studies carried out by NASA in 2012 revealed that the experimental model and the numerical geometry provided by the DPW Committee have different wing twists at the design point. In this article, even if experimental data is used for some comparisons, only the original wing of the DPW-4/5 will be used. Fig. 1 shows the complete configuration. 


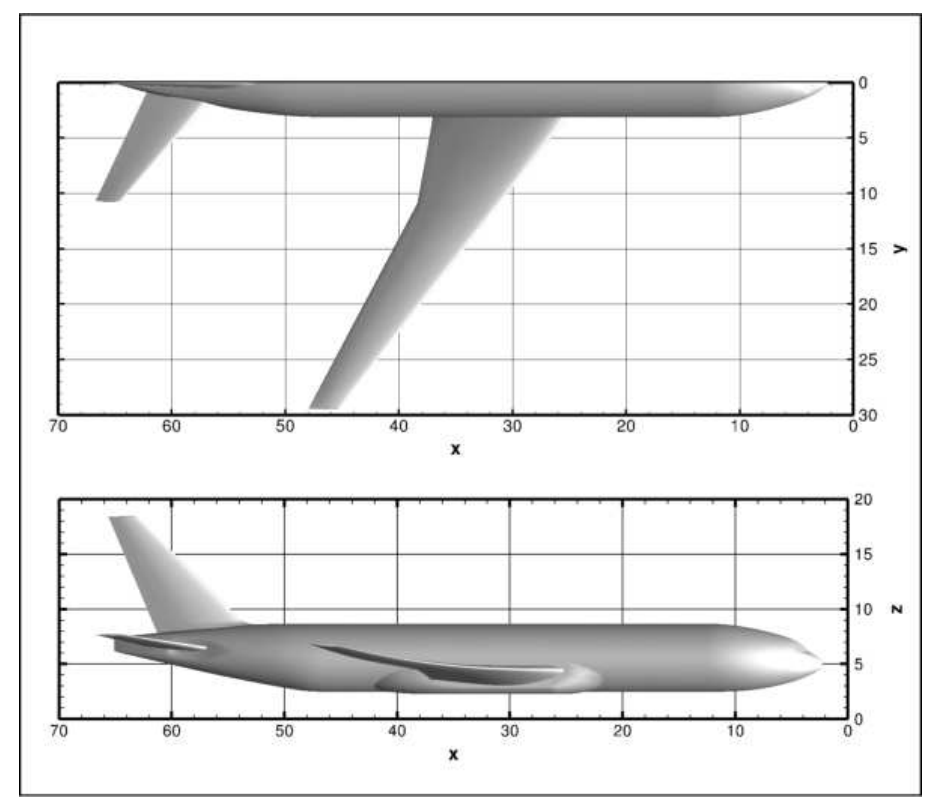

Fig. 1 The Common Research Model in meters.

As it can be noticed, the CRM exhibited in Fig. 1 has a Vertical Tail Plane (VTP). The VTP geometry has not been provided by the DPW Committee: it has been designed by the Applied Aerodynamics Department of ONERA. Indeed, with the authorization of NASA, the ONERA is planning to carry out test campaigns using its own CRM model. This configuration will be used as a reference model for the largest ONERA wind tunnel (S1). In this context, the design of a VTP has been completed. The Computer-Aided Design (CAD) geometry of this new element has been recently shared with NASA.

In Fig. 1, it can be observed that the original CRM geometry already includes a functional area on the upper part of the rear fuselage which perfectly corresponds to the location of a VTP. This hollow partly compensates the volume effect of the vertical tail on the fuselage, thus mitigating local drag rise and flow separation risk. The VTP planform defined at ONERA has the following characteristics: projected surface of $56 \mathrm{~m}^{2}$, a root chord of $7.935 \mathrm{~m}$, a tip chord of $2.576 \mathrm{~m}$, a leading edge sweep angle of $44.5^{\circ}$, and a trailing edge sweep angle of $22.2^{\circ}$. As a consequence, the VTP is about 10 meters high. Once the planform has been set, a NACA-64A011 airfoil exhibiting $13.42 \%$ of relative thickness has been chosen to generate the three-dimensional (3D) shape. This airfoil is considered as suitable for such purposes, having a maximum thickness close to the mid chord. 


\section{B. CRM Element by Element}

All the CRM elements (fuselage, wing, HTP at $0^{\circ}$, VTP) mentioned in the former paragraph will be used in this paper. As said previously, these basic pieces will be meshed independently. To illustrate this approach, Fig. 2 exhibits the CRM breakdown: each element is considered separately. Moreover, as it can be noticed, for meshing purposes, a part of the fuselage surface will be used in order to build the near-body grids of the other elements.

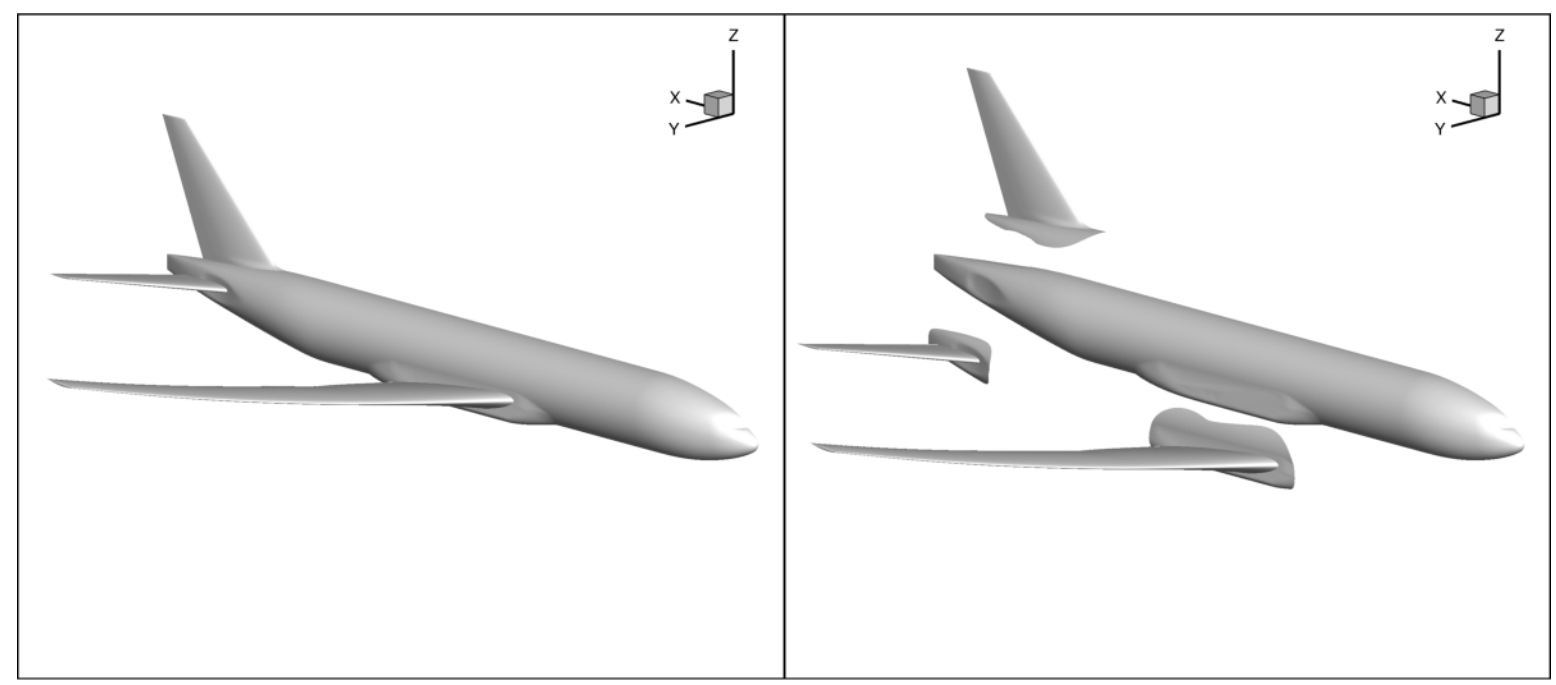

Fig. 2 The CRM as a multi-element configuration.

\section{Reference Grids and Data}

In order to compare and validate the results obtained with the ONERA meshing approach presented in this article, some reference grids and data are required. As mentioned in the introduction, the literature focusing on the CRM is abundant. In the framework of the Drag Prediction Workshops, many grids and results have been made available for all the DPW community.

Concerning grids, the family of point-matched multiblock meshes provided by the DPW-5 Committee for the CRM wing-body configuration will be used [28]. These structured grids have produced very satisfactory results and quite good agreement with the National Transonic Facility (NTF) experimental data [25]. The different characteristics of these meshes are indicated in Table 1: 
Table 1 Common multi-block grids for the WB configuration

\begin{tabular}{|c|c|c|c|}
\hline Level & Name & Number of cells (millions) & $\boldsymbol{Y}^{+}$ \\
\hline L1 & Tiny & 0.64 & 2.00 \\
\hline L2 & Coarse & 2.16 & 1.33 \\
\hline L3 & Medium & 5.11 & 1.00 \\
\hline L4 & Fine & 17.25 & 0.67 \\
\hline L5 & Extra-Fine & 40.89 & 0.50 \\
\hline L6 & Super-Fine & 138.02 & 0.33 \\
\hline
\end{tabular}

Sizes of these grids range from 638,976 to $138,018,816$ cells, exhibiting a grid size ratio of 216 . They are O-type grids obtained by an hyperbolic mesh generation tool starting from a discretization of the surfaces (see Fig. 3). They are made of 5 structured blocks. Grid quality, i.e. grid spacing, stretching ratio and grid orthogonality, is well controlled using this mesh generation method. The height of the first cell next to the wall varies from $Y^{+}=2.00$ for the tiny grid to $Y^{+}=0.33$ for the super-fine mesh. The mesh extent is greater than 100 mean-aerodynamic chords. An illustration of the refinement levels is given in Fig. 3. If the expected accuracy for drag prediction is below the count $\left(1 \mathrm{drag}\right.$ count $\left.=10^{-4}\right)$, the grid convergence study shown in [25] indicates that the fourth refinement level (L4 / 17 million elements) is sufficient to evaluate the aerodynamic coefficients correctly.

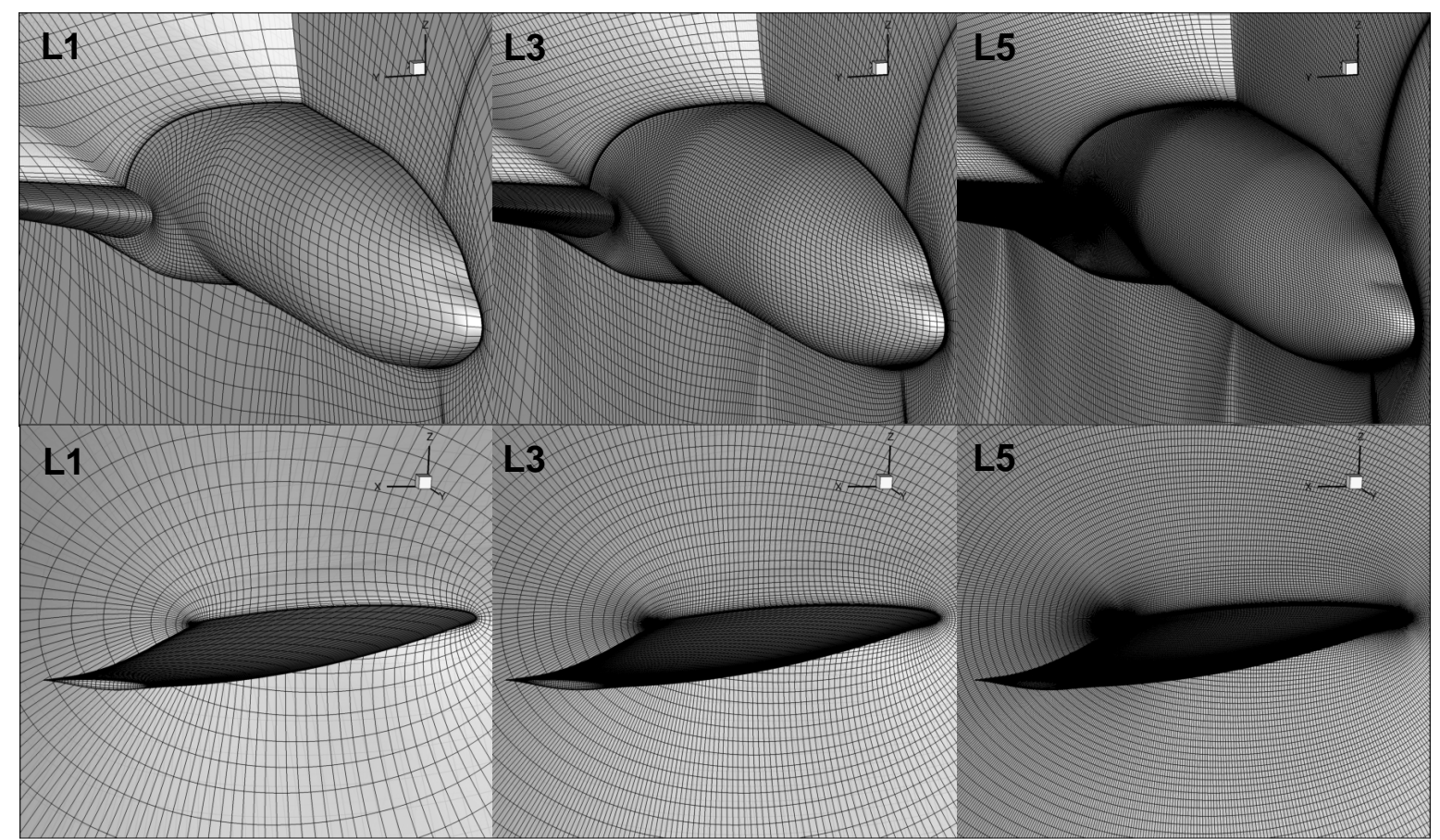

Fig. 3 Common multiblock meshes: refinement levels L1, L3, L5. 
Concerning reference data for the wing-body configuration at the design point $(M a=0.85, \operatorname{Re}=5$ millions, $C L=$ 0.5), the experimental measurement in NTF [29] gives a drag level of 248 counts. However, as said previously, the NTF model and numerical CAD have slightly different wing twists. Furthermore, in the experiments, laminar zones were present up to $10 \%$ chord while the DPW computations are fully turbulent. These discrepancies clearly impact the agreement that can be achieved, as shown in [26]. As a consequence, the closest reference data that can be used for this paper correspond to the numerical results obtained with the DPW-5 common grids described above. Some of these outcomes are presented in [25], they include near-field and far-field components. Since the grid converged value of drag obtained by ONERA is equal to the CFD median of all DPW-5 participants [30], the confidence in the following values can be considered as satisfactory: the expected total drag value for the CRM wing-body configuration is 250 drag counts: 135 counts of pressure drag, and 115 counts of friction drag.

To evaluate the results which will be obtained with the Horizontal Tail Plane, the ONERA results obtained in the context of DPW-4 will be considered. The drag variation observed in [24] when adding the HTP to the wing-body will be used as reference value. Moreover, the NTF data, which includes test configurations with the tail, will also be given.

Concerning the Vertical Tail Plane, as no data exists today, the validation of results will have to wait the coming ONERA test campaigns. Nevertheless, it is used in this article for two reasons: first, to highlight the flexibility of the chosen mesh strategy and then to share this new CRM element with the community.

\section{Near-body and Cartesian Off-body Grids: an Overset Approach}

\section{A. Steps and Advantages of the Approach}

Since the concept of near-body/off-body mesh partitioning of the computational domain is described in the introduction, only the main steps are presented here:

1) A set of near-body structured grids is built around each element of the configuration by using dedicated software. The grids defining the different elements may exhibit overlapping areas;

2) Off-body Cartesian grids are automatically generated;

3) Overset grid assembly between overlapping grids obtained in steps 1 and 2 is completed. 
This approach has several advantages:

1) Volume grids are obtained by extruding surface abutting grids defining each element, resulting in O-type or C-type meshes: no expertise is required to define the blocking of the whole configuration, as it should be done when using transfinite interpolation method. As a consequence, in comparison with a good-quality mesh using a structured classical multiblock approach, the mesh generation step is significantly reduced.

2) Since the present approach takes advantage of the flexibility of the overset method, it is perfectly suitable for handling configurations where elements such as tail planes, nacelles or winglets are likely to be added or removed, whereas the whole mesh should be rebuilt using a multiblock approach.

3) Cartesian off-body grids are adapted to the spatial resolution of near-body grids at their external borders, where overset interpolations occur, ensuring a correct grid assembly between near and off-body grids.

4) Cartesian off-body grids can be easily adapted according to physical criteria, resulting in a better capture of flow features, such as wakes and shocks.

To conclude, since this meshing approach is based on overset techniques, it must be said that a certain expertise in this field is required in order to apply it efficiently. The interactions (overset interpolations) between the near-body and Cartesian grids should be managed carefully.

\section{B. Near-body Grids}

To illustrate the generation of the body-fitted curvilinear grids, the CRM elements which have been presented in section II will be used as examples. This step should be realized using dedicated meshing software. In this study, Pointwise [16] has been used. It is an efficient meshing tool which allows to generate satisfactory 3D grids (automatic extrusion) from a surface discretization defined by the user. All the near-body grids presented here are basic O-type grids but C-type grids can be done as well. As it has been proved as sufficient, the refinement of the mesh L4 has been used as an example for the surface grids which are shown below.

Because of its importance in terms of aerodynamics, the mesh around the wing is the first to be presented. The 2D surface discretization which has been imposed is given in Fig. 4 and Fig. 5. The chord is defined by 165 points while there is 150 points in the spanwise direction. The refinement of the latter is greater in the root and tip areas. As mentioned previously, the mesh around the wing must lean against the fuselage surface in order to represent the wing-body junction; otherwise, a collar grid would be necessary. A particular aspect of this area, which is visible in 
Fig. 5, is the fact that the spanwise and normal point distributions at the root both start with micrometric cells. The mesh topology is quite different in the $\mathrm{L}_{\mathrm{i}}$ family: the micrometric distribution is imposed on the bisector of the wing body junction (see Fig. 3). It will be demonstrated that this difference has an impact on the side-of-body flow separation prediction. If configurations more realistic are considered, this type of junctions (corners) may be smoothed with fillets but it would not affect the methodology: the near-body grid of the wing would be generated according to the specific junction.

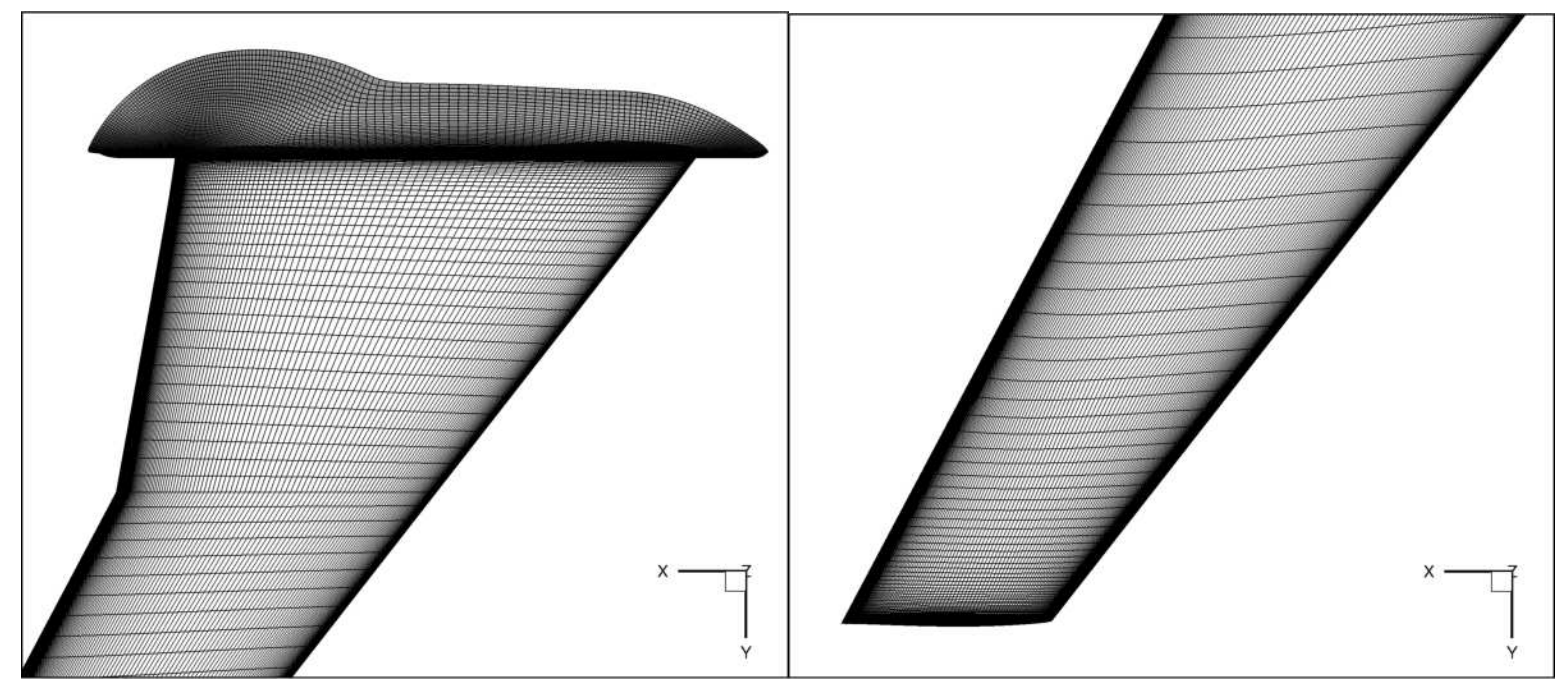

Fig. 4 Surface discretization of the wing: root and tip areas.

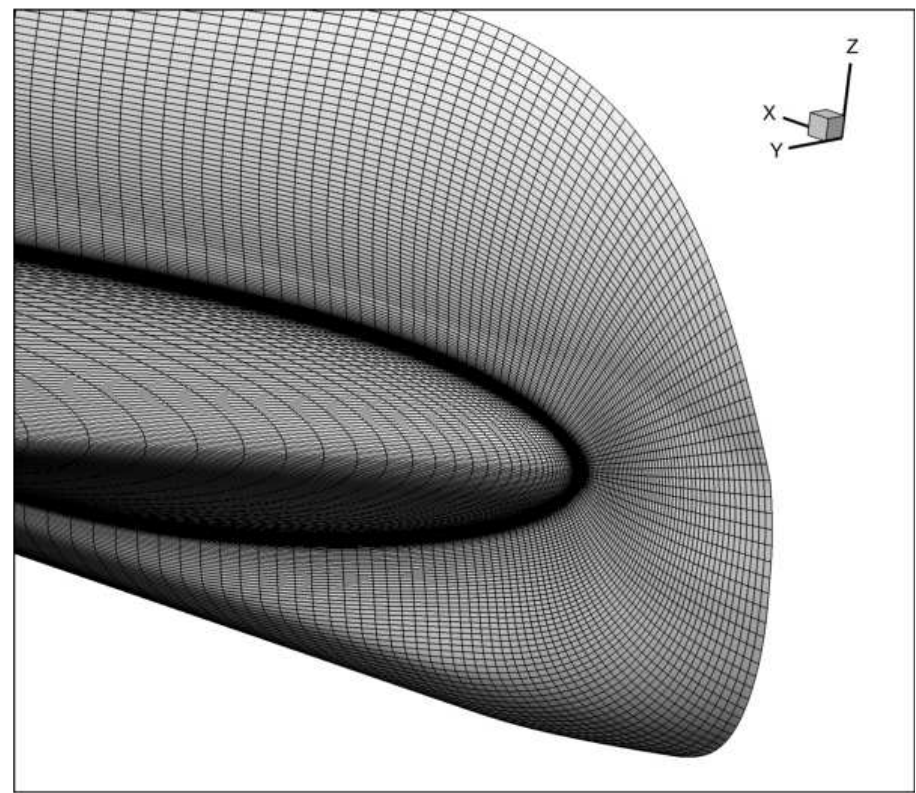

Fig. 5 Wing-body junction: micrometric distributions in spanwise and normal directions. 
A close-up view of the resulting mesh around the wing in a section along the span is displayed in Fig. 6, showing the structure of the O-type mesh. As it can be observed, very satisfactory grid orthogonality to the walls is ensured. Directly at the skin, the extrusion is performed in a way such that several cell layers have the same height. Then, a low stretching ratio (1.15) is applied to build the cells aimed at describing the boundary layer (50 points in the normal direction). Finally, cell layers are added to adjust the mesh extent. As it can be seen in Fig. 6, the cell height is quite uniform at external borders of near-body grids, in order to ensure good-quality overset transfers from offbody to near-body grids. For the wing, the mesh extent is quite large. Indeed, in transonic conditions, a supersonic zone going over the curvilinear mesh might be insufficiently described under certain circumstances. In order to prevent this, the extent has been chosen such as the supersonic areas remain deeply inside the near-body mesh. Furthermore, a special care has been given to the trailing edge area refinement, as is the case for the $\mathrm{L}_{\mathrm{i}}$ family (see Fig. 3). The close-up view in Fig. 6 shows that the refinement on the blunt trailing edge (9 points) imposes a high point density in the rear part of the airfoil: this aspect is of prime importance for O-type grids. The complete wing mesh is shown in Fig. 7. Several cuts represent the O-grids around different wing sections and the right-hand side figure exhibits the global outer border. It can be noticed that the wing mesh extent is significantly reduced at the root in order to match the surface fuselage used for the wing-body junction. In practice, the required time frame to realize such a mesh is one day. It is composed of about 6 million elements.

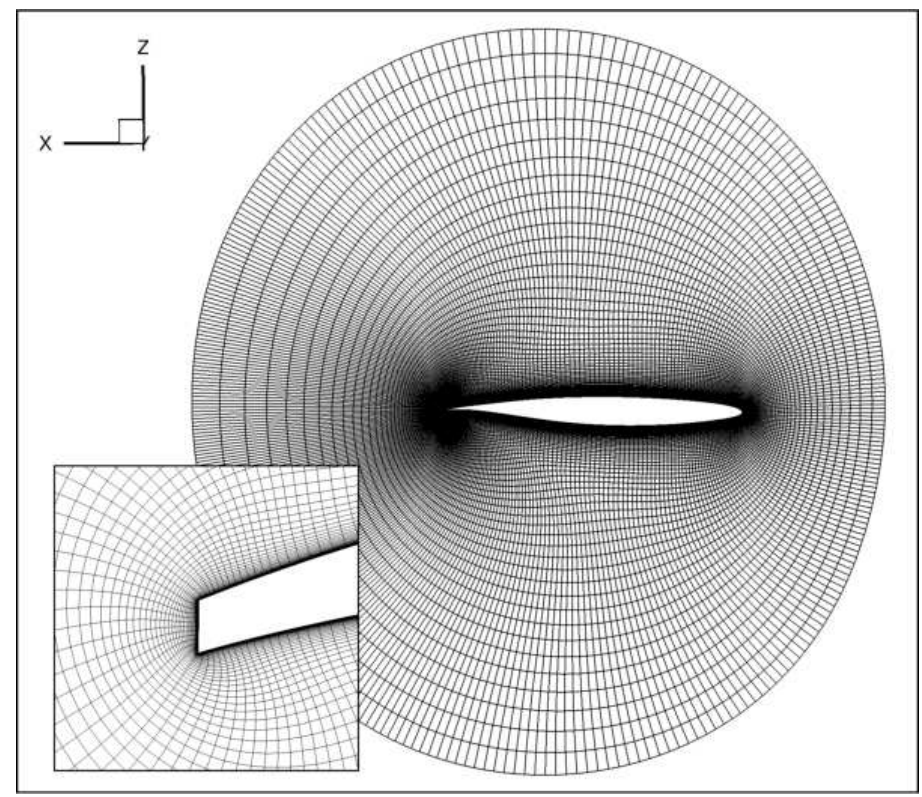

Fig. 6 O-type mesh around the wing airfoil: close-up view at the blunt trailing edge. 


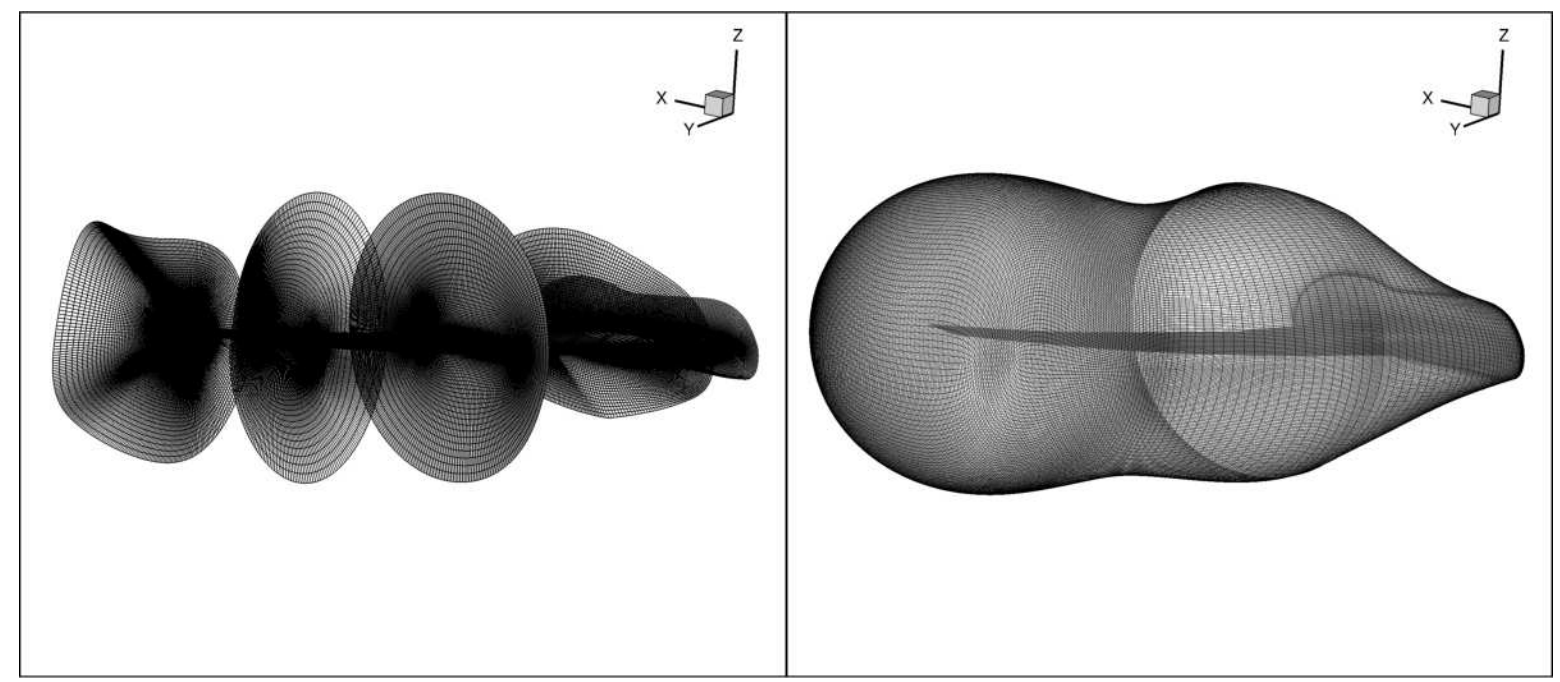

Fig. 7 Full near-body mesh of the CRM wing.

The grids of the horizontal and vertical tailplanes are generated using the same method as for the wing. Once the surface mesh is defined, the extrusion is performed in order to obtain a satisfactory 3D mesh. For these elements, as no shocks exist at the design point, the extent can be more limited. The HTP mesh is made of about 1.8 million cells. It is shown in Fig. 8 and Fig. 9.

In terms of topology and aspect, the vertical tailplane grid shape is equivalent to the HTP mesh. Nevertheless, the refinement level is lower for the VTP. It only includes 0.8 million elements. This is due to the fact that fewer aerodynamic interactions are expected in this area. Another difference with the wing and HTP grids is the fact that a symmetry plane condition is needed here, the VTP being, as the fuselage, a half configuration. Fig. 10 shows the complete mesh of the vertical tail. For sake of clarity, the cut at mid-chord is blanked after mid-span. 


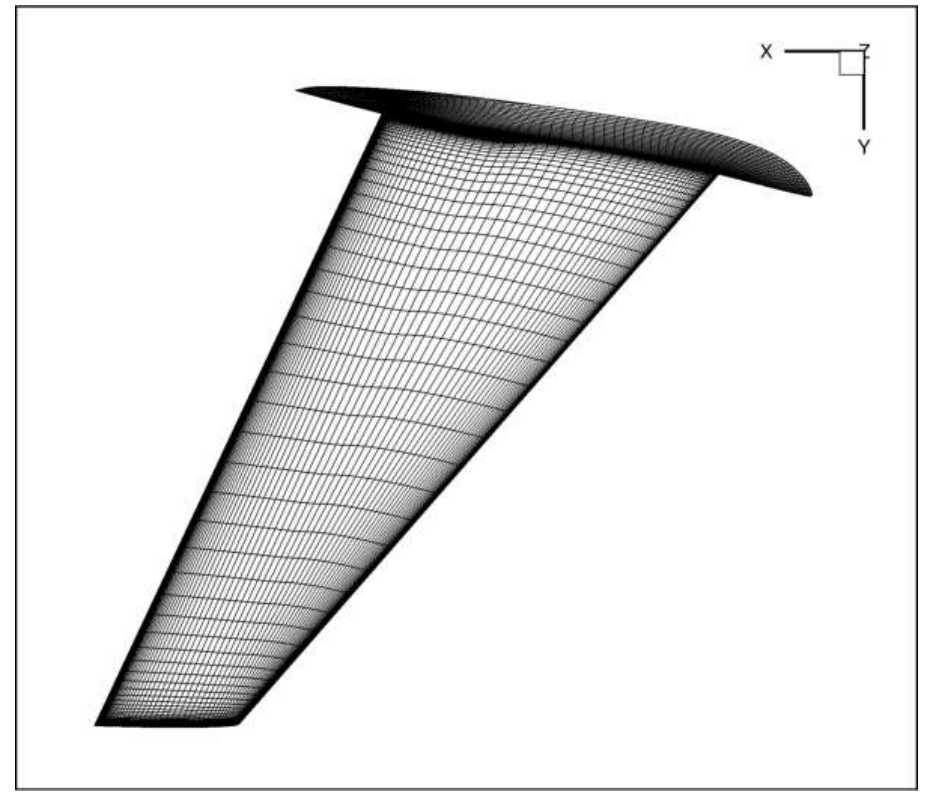

Fig. 8 HTP surface discretization.

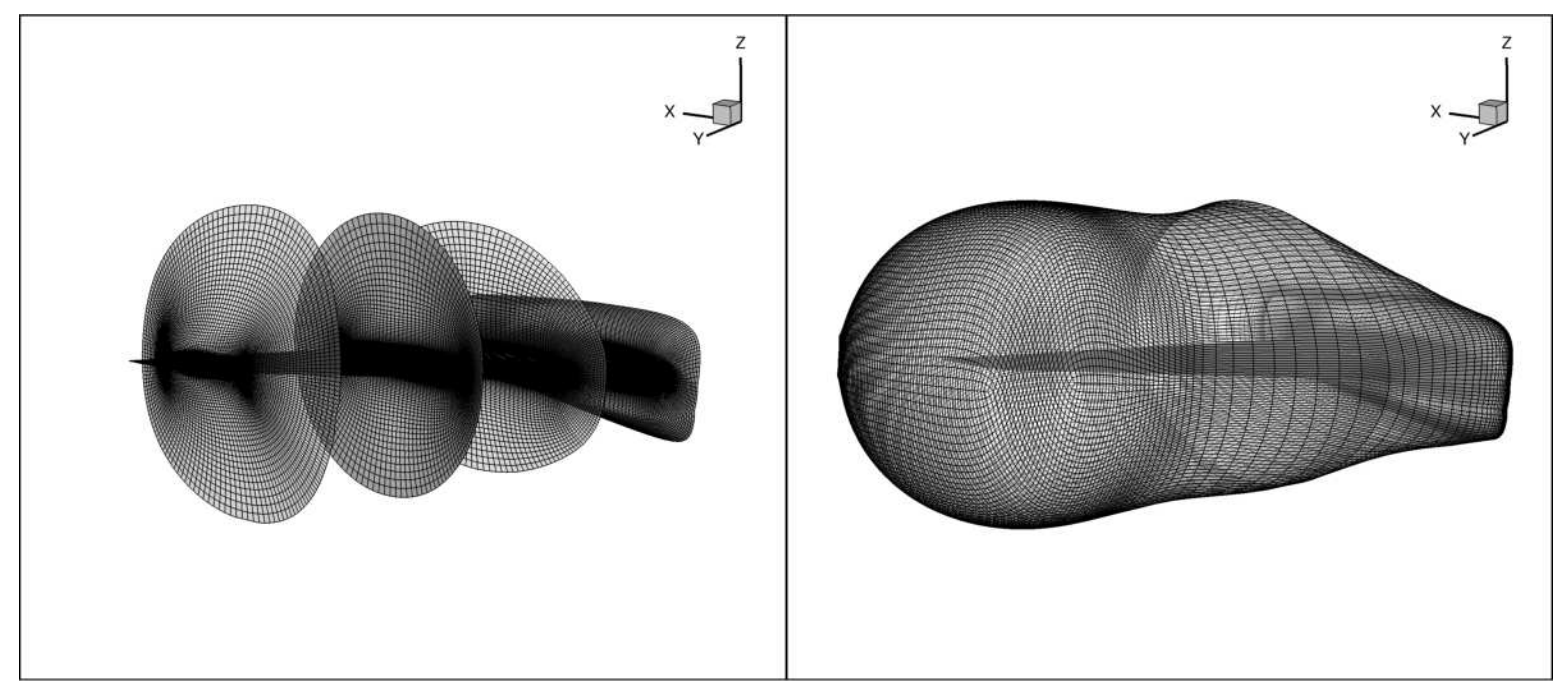

Fig. 9 Complete HTP mesh. 


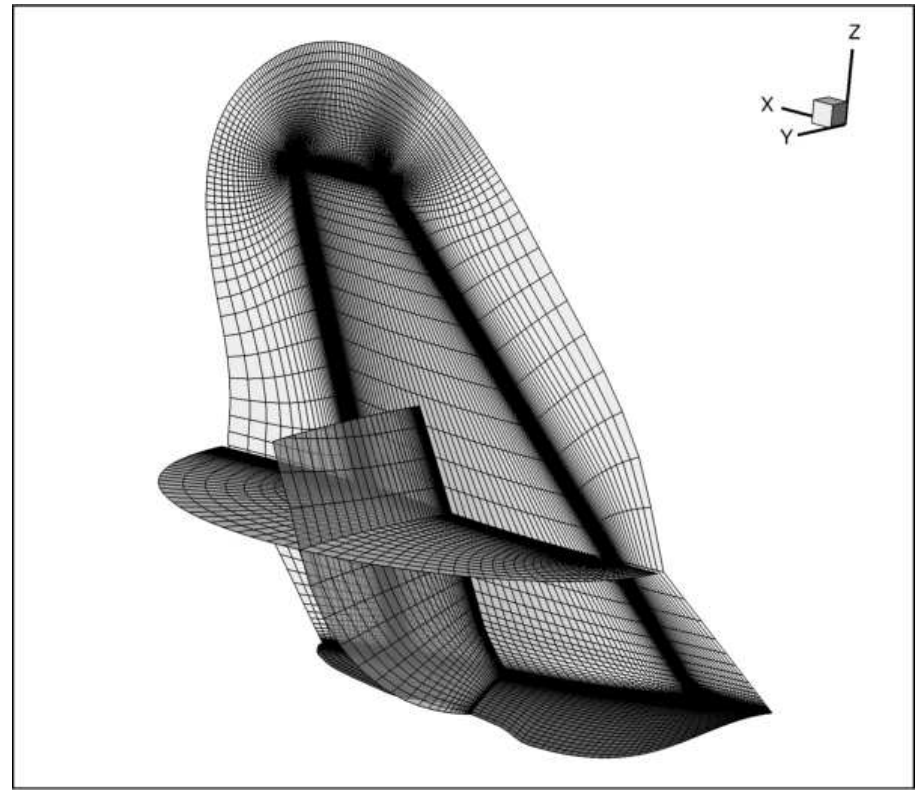

Fig. 10 Complete VTP mesh.

The fuselage mesh generation is clearly the less complex since no junction exists. As it can be seen in Fig. 11, this mesh is simply a semi-cylinder surrounding the surface. Nevertheless, the point distribution in the longitudinal direction must be refined enough to ensure a good overset assembly with the grids defining the other elements. This can be an iterative process. In practice, meshing such a simple geometry with Pointwise software requires less than half a day. The mesh presented in Fig. 11 is composed by 4.6 million cells.

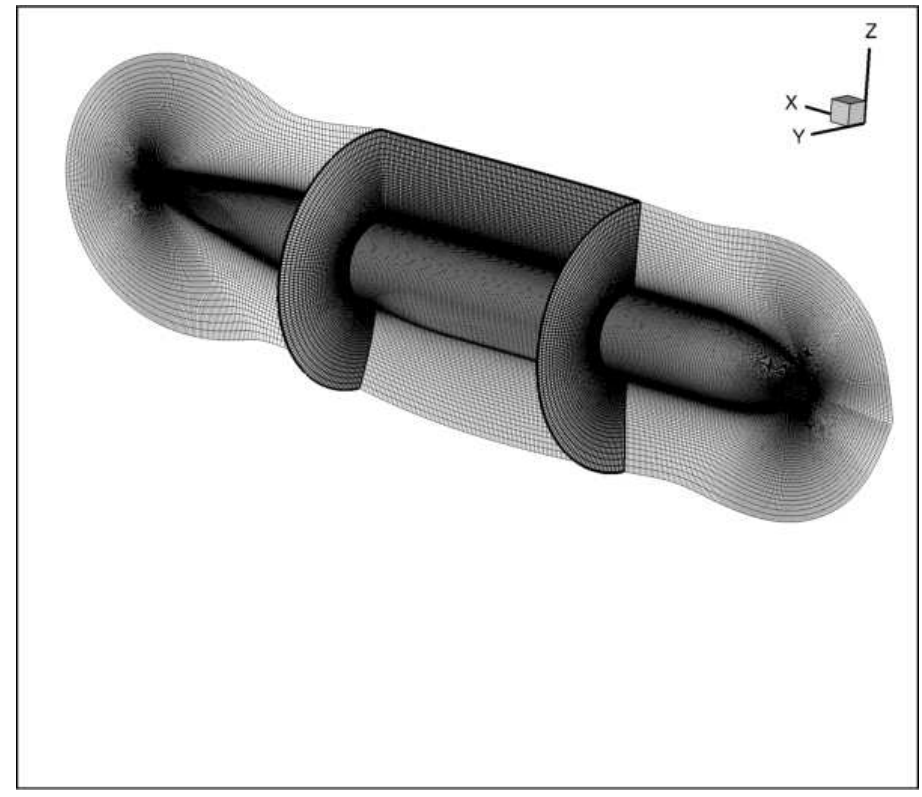

Fig. 11 Complete fuselage mesh. 
To conclude about the near-body grid mesh generation, the extrusion process described for the wing mesh is identical for all the CRM elements which have been presented above (good mesh orthogonality, several skin cell layers of same height, a low growth ratio, about 50 cells in the boundary layer, an adjusted extent). Also, with efficient software, clean CAD models, and a little expertise, the meshing step consisting in creating near-body grids for the WB-HTP-VTP configuration can be completed in less than a week.

\section{Off-body Cartesian Grids}

The off-body Cartesian mesh overlapping near-body grids is generated automatically using Cassiopee functions [9]. The skeleton of the Cartesian set of uniform grids relies on an octree unstructured mesh, as detailed in [8]. This octree mesh is built from the surfaces defined by the wall borders of the near-body grids. A spacing parameter is then required in the vicinity of each surface and also the extent of the computational domain, which is 100 mean aerodynamic chords in this case (i.e. about 700 meters). Each element of the unstructured octree mesh defines a Cartesian elementary grid. Finally, Cartesian grids are abutting in a patch-grid fashion, as described in Fig. 12. The largest cells are $52 \mathrm{~m}$ long while the smallest ones are $0.2 \mathrm{~m}$ long. In this process, it is important to keep in mind that the size of the smallest Cartesian cells must be chosen similar to the cell size at external borders of near-body grids. This is ensured by the generation of the octree. Fig. 13 shows the Cartesian mesh around the aircraft position. As expected, the Cartesian box exhibits a strong refinement close to the near-body meshes. Furthermore, the cell size between near-body and Cartesian grids is of same magnitude in regions where overset interpolations are expected, in order to keep interpolation errors as small as possible during overset transfers.

Since the input surfaces provided to generate the Cartesian box are defined by the aircraft surfaces in this example, the Cartesian grid gets coarser a few meters downstream of the plane, as it can be seen with Fig. 13 and Fig. 14. Depending on the type of studies which are carried out, this particularity might be a problem. As it will be shown thereafter, a feature-based Cartesian mesh adaptation is a way of handling this aspect.

In practice, the time frame required to generate the off-body Cartesian mesh is not significant once the surfaces provided to generate the octree are defined (a few minutes). The resulting Cartesian mesh for the CRM Wing-Body configuration is composed by about 6 million cells. The number of points slightly grows for the CRM WB-HTPVTP configuration. 


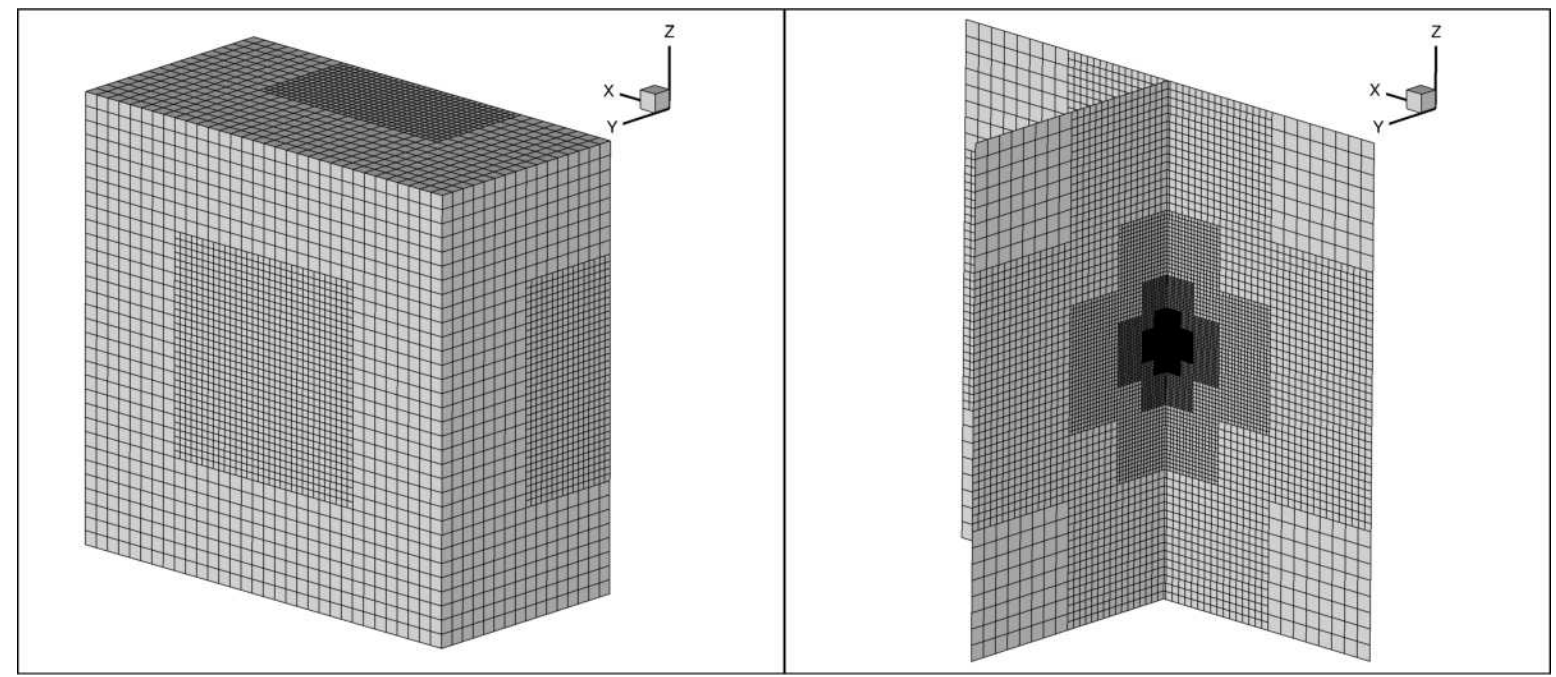

Fig. 12 Cartesian mesh: the whole box.

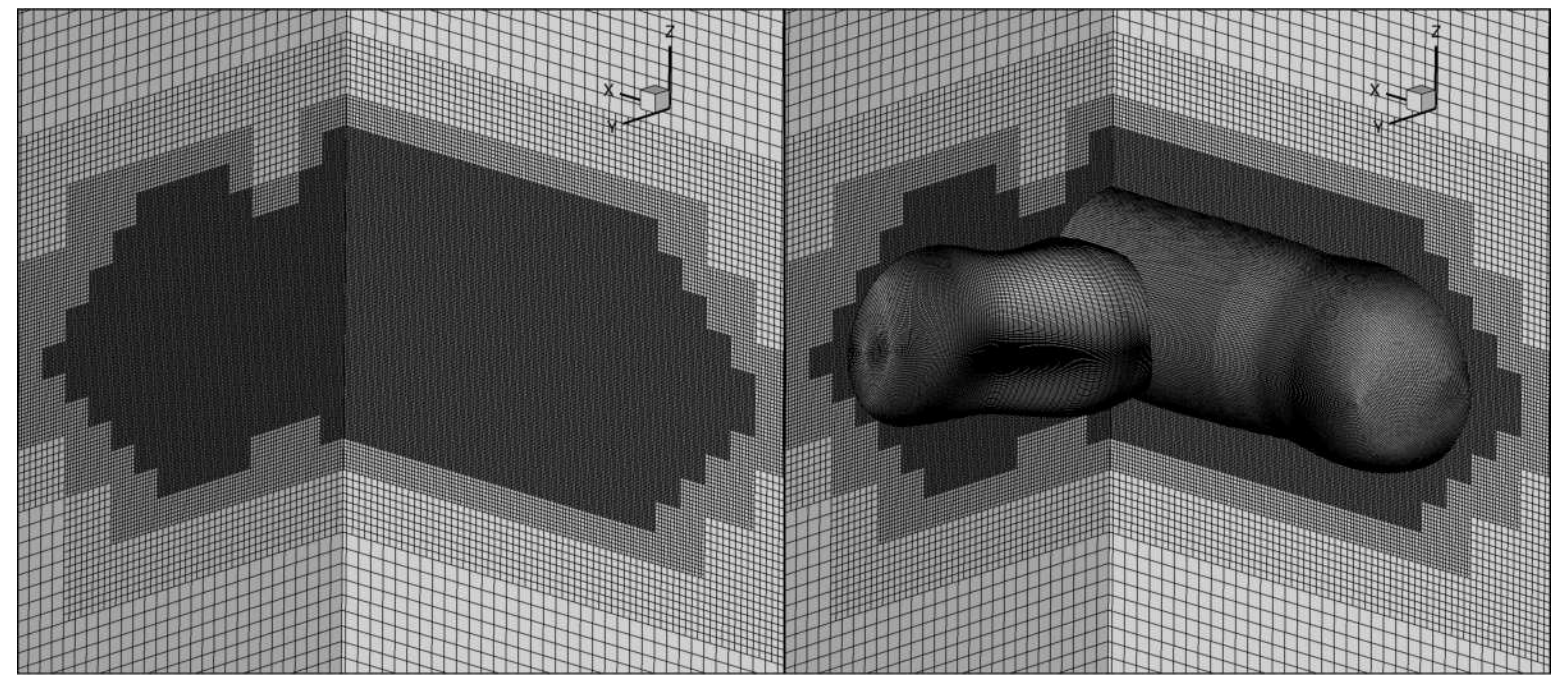

Fig. 13 Cartesian mesh: zoom on the CRM WB position (without and with near-body grids). 


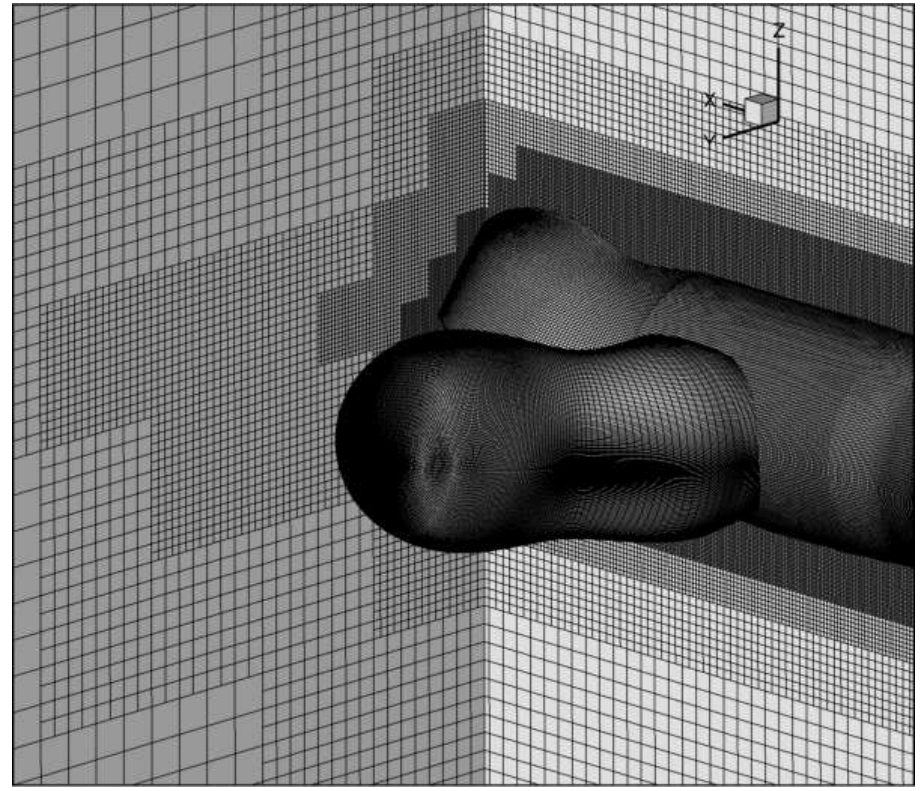

Fig. 14 Cartesian mesh: coarsening in the CRM WB wake (with near-body grids).

\section{Overset Grid Assembly}

Once the near-body grids and Cartesian box are available, the overset assembly needs to be completed. This assembly is performed using Cassiopée modules [9, 18].

First, grid cells that lie inside bodies are blanked out according to assembly rules, as detailed in [17]. A slice in the spanwise direction is displayed in Fig. 15, exhibiting the large overlapping between the Cartesian and the nearbody meshes around the wing. In order to mark Cartesian grid cells as solid points inside the body, the wing surface is defined as the blanking body. To prevent overset interpolations from occurring in the boundary layer, the blanking region can be enlarged of a distance delta. This distance is provided to the blanking function as a parameter. The result of this operation is given in Fig. 16. In this approach, two layers of interpolated cells are defined at the fringe of blanked cells, and at external borders of near-body grids. Consequently, the delta parameter provided by the user must be carefully chosen to ensure a grid overlapping that enables to find valid donor cells for both grids.

As an alternative way to extend the blanked region, an overlap optimization can be performed to reduce automatically the overlapping between grids. This step enables to limit the areas of co-existent solutions, which usually improves the convergence of the CFD computation, as it will be demonstrated thereafter.

The overlap optimization algorithm is based on the algorithm developed in Pegasus [10], giving priority to the cells of smallest volume in overlapping regions. Since the smallest cells can be alternatively in a grid or another grid 
locally, resulting in spots of computed regions in both grids, an element can be of higher priority regarding other elements. For instance, the wing mesh can be of higher priority than the fuselage, then, its grid cells are favored in wing / fuselage overlapping regions. When applying the same priority to some elements, the criterion to favor a grid cell to another one is based on the smallest volume. In practice, the overlap optimization method is performed in a sequential mode. Thus, with the grids presented here, it can last more than one hour, whereas the blanking itself requires only a few minutes.

The result of the blanking followed by the overlap optimization between the wing and the Cartesian meshes (with a priority given to the wing mesh) is displayed in Fig. 17, showing that the overlapping region is significantly reduced. No orphan cell appears due to this overlap reduction and overset transfers between both grids occur far from the boundary layer. Note that cell sizes are of same magnitude in interpolation areas.

When walls are described twice by overlapping grids, for example the wing-body junction with two different near-body grids of fuselage and wing, a projection algorithm is performed to correctly compute donor cells and overset interpolation coefficients. This kind of technique is described in [31].

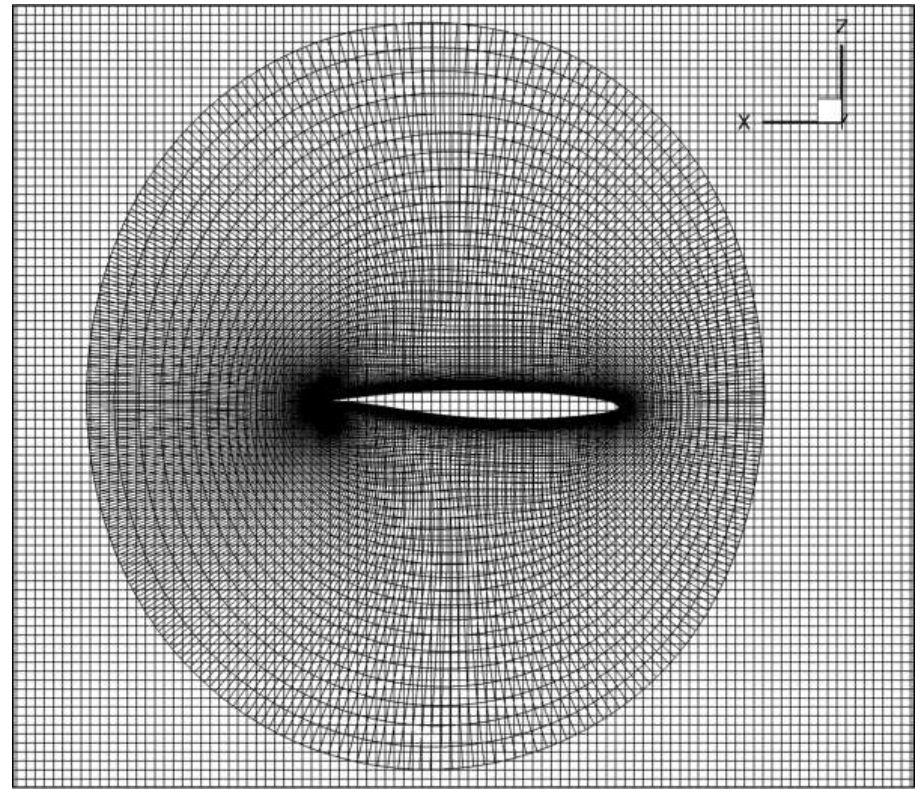

Fig. 15 The overlapping issue. 


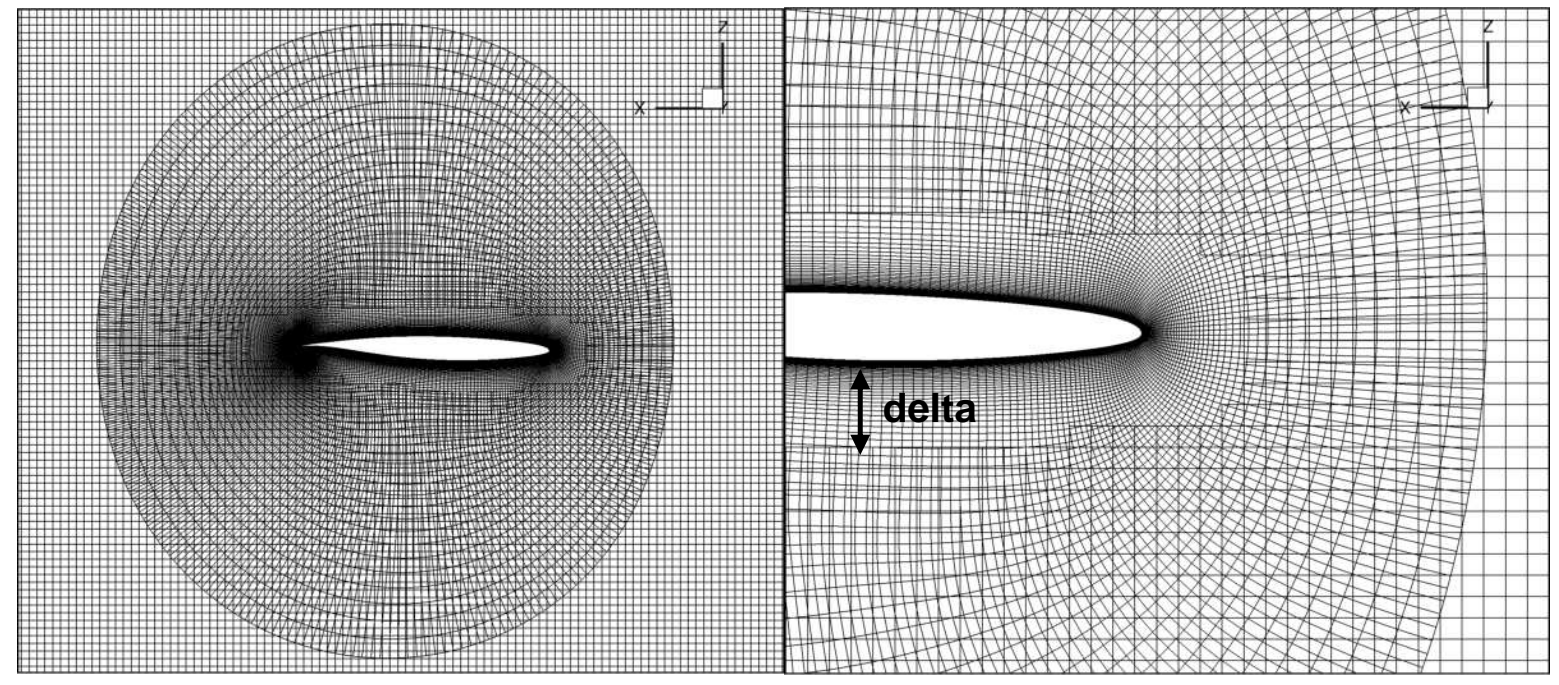

Fig. 16 Blanking of Cartesian grid cells.

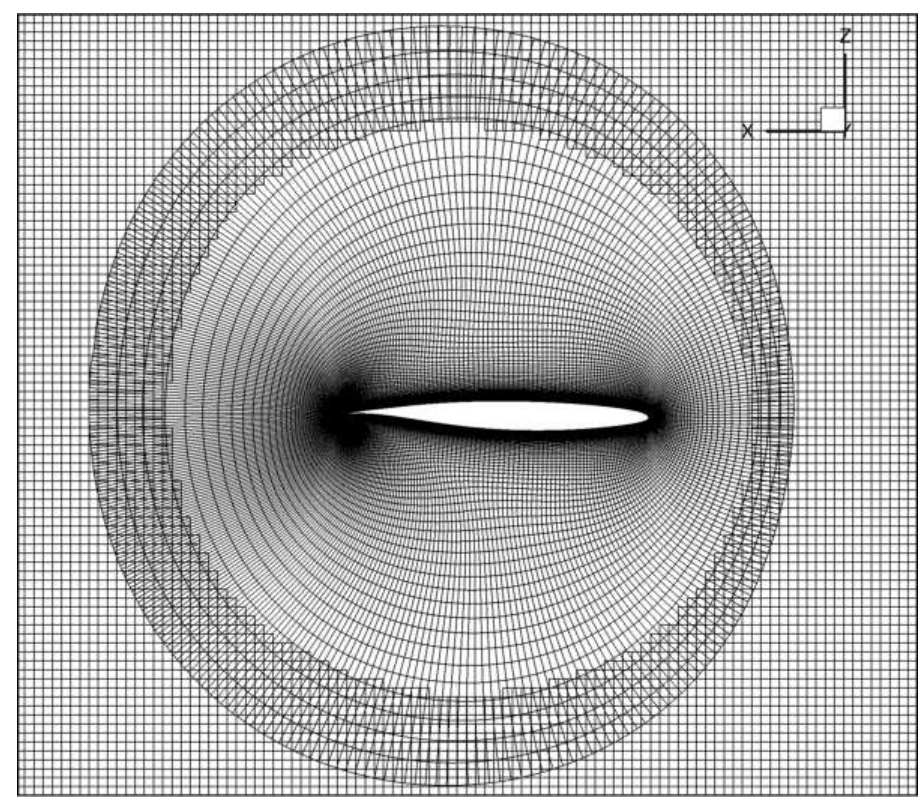

Fig. 17 Overlap optimization.

\section{E. Sets of Grids used in this Study}

\section{1st Set of Grids}

The first set of grids used in this paper corresponds to the meshes which have been shown to explain the nearbody / Cartesian off-body mesh partitioning of the computational domain. 
Depending on the elements and blanking methods which are used, several global meshes can be created from the pieces which have been presented above. The first one, which will be called $\mathrm{O}_{0}$, corresponds to the Wing-Body configuration without overlap optimization (Fig. 16). The second mesh which is considered is O1: it is still the WB configuration but with overlap optimization (Fig. 17 ). The results obtained with these two grids can be directly compared to the studies which have been carried out using the $\mathrm{L}_{\mathrm{i}}$ family. Then, the mesh $\mathrm{O} 2$ is composed of the WB configuration on which the HTP is added. Finally, the mesh O3 corresponds to the full configuration: WB-HTPVTP. An illustration is given in Fig. 18. An overlap optimization has been applied for these grids. The priority order for the overlap optimization is the following (starting by the highest priority): Wing, HTP, VTP (for O3), Body, Cartesian mesh.

The Cartesian mesh is used in all these grids. Their characteristics are summarized in Table 2. As it can be observed, these grids are comparable to the L4 mesh in term of number of cells.

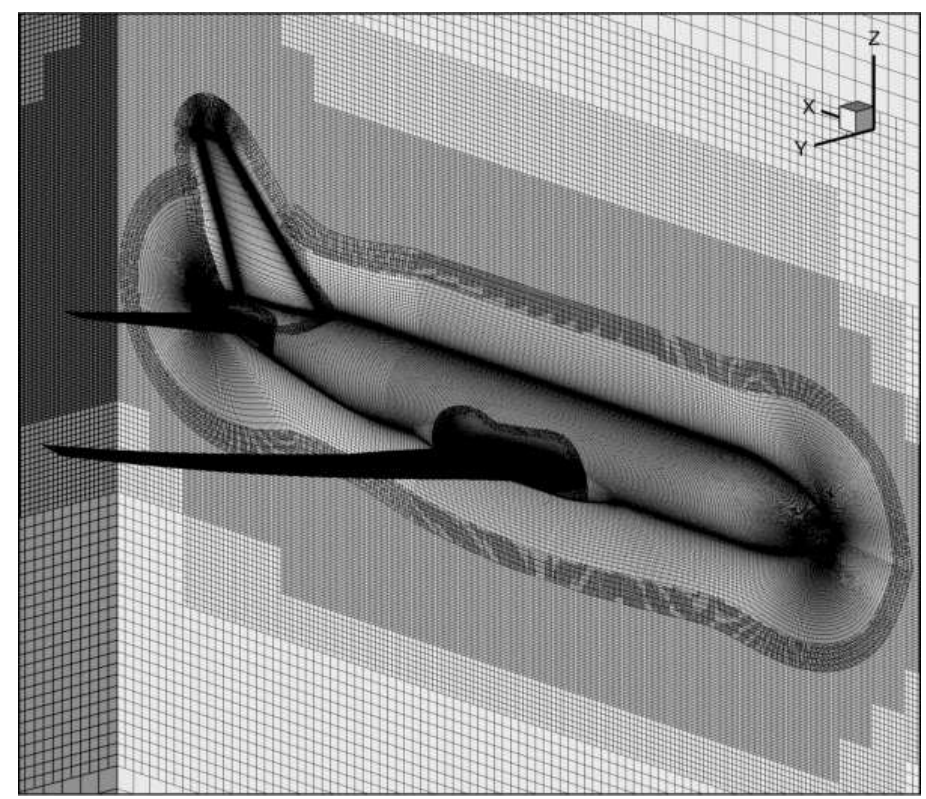

Fig. 18 Full mesh for the configuration WB-HTP-VTP (O3).

Table 2 ONERA overset grids

\begin{tabular}{|c|c|c|c|}
\hline Name & Configuration & Number of cells (millions) & $\boldsymbol{Y}^{+}$ \\
\hline $\mathbf{O 1}_{\mathbf{0}}$ & WB w/o overlap optimization & 16.60 & 0.4 to 0.6 \\
\hline $\mathbf{O 1}$ & WB & 16.60 & 0.4 to 0.6 \\
\hline $\mathbf{O 2}$ & WB-HTP & 18.96 & 0.4 to 0.6 \\
\hline $\mathbf{O 3}$ & WB-HTP-VTP & 20.17 & 0.4 to 0.6 \\
\hline
\end{tabular}




\section{2nd Set of Grids}

This second set of grids is based on the same method as previously. Some of these have already been shown in the reference [25]. They are a combination of the DPW-5 common multi-block grids and ONERA Cartesian grids. As a consequence, only the Wing-Body configuration is concerned. These grids are used in this article for two reasons. First, since the near-body grids are rigorously identical to the ones of the $\mathrm{L}_{\mathrm{i}}$ family, the comparison is meaningful. In addition, in this study, Cartesian mesh adaptation has been performed on these meshes.

As these grids are mixed DPW-ONERA meshes, they will be named DO. Two refinement levels have been tested: DO1 and DO2. The near-body grids have been directly extracted from the common grids L2 and L4 respectively (see Table 1). Unlike the first set of meshes, the Wing-Body is described by a single multiblock nearbody mesh. The extent of the near-body mesh surrounding the aircraft is equal to one meter, as it can be observed in Fig. 19. Due to this small extent, no overlap optimization is performed between near-body and off-body grids. The Cartesian mesh of DO1 is obtained by coarsening the Cartesian mesh of DO2 by a factor 2 in all the directions (Fig. 20). Besides, the DO1 Cartesian mesh has been adapted according to the turbulent viscosity, in order to compensate the small extent of near-body grids and the resulting mesh is then called DO $1_{\mathrm{a}}$. Results obtained with this adaptation will be shown in section VI.C. The global mesh extent for all refinement levels is greater than 100 meanaerodynamic chords. The different characteristics of the DPW-ONERA meshes are indicated in Table 3. As the Cartesian mesh is set to be very refined here, it can be noticed that DO1 and DO2 are respectively greater than L2 and L4 in term of number of cells (see Table 1). On the other hand, the Cartesian adaptation exhibits a reasonable cost in terms of additional cells $(+30 \%)$.

Table 3 DPW-ONERA overset grids

\begin{tabular}{|c|c|c|c|}
\hline Name & Configuration & Number of cells & $\boldsymbol{Y}^{+}$ \\
\hline DO1 & WB w/o overlap optimization & 3.98 & 1.33 \\
\hline DO1 $_{\mathbf{a}}$ & WB w/o overlap optimization w/ adaptation & 5.15 & 1.33 \\
\hline DO2 & WB w/o overlap optimization & 31.46 & 0.67 \\
\hline
\end{tabular}




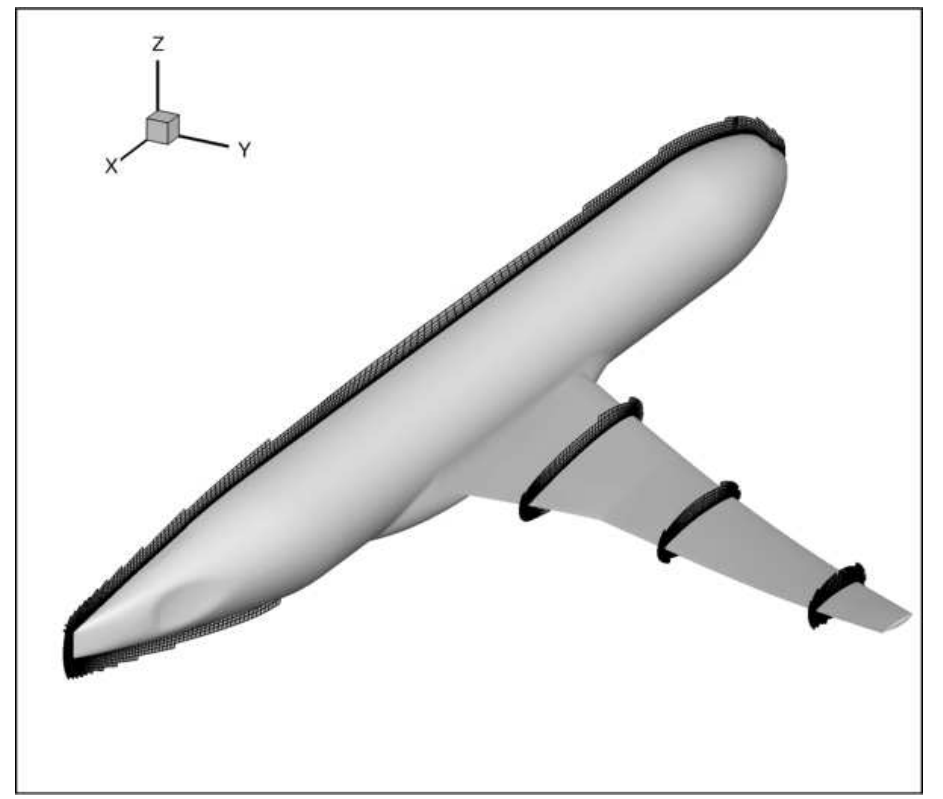

Fig. 19 Near-body mesh of DO1 corresponding to the $1^{\text {st }}$ meter of L2.

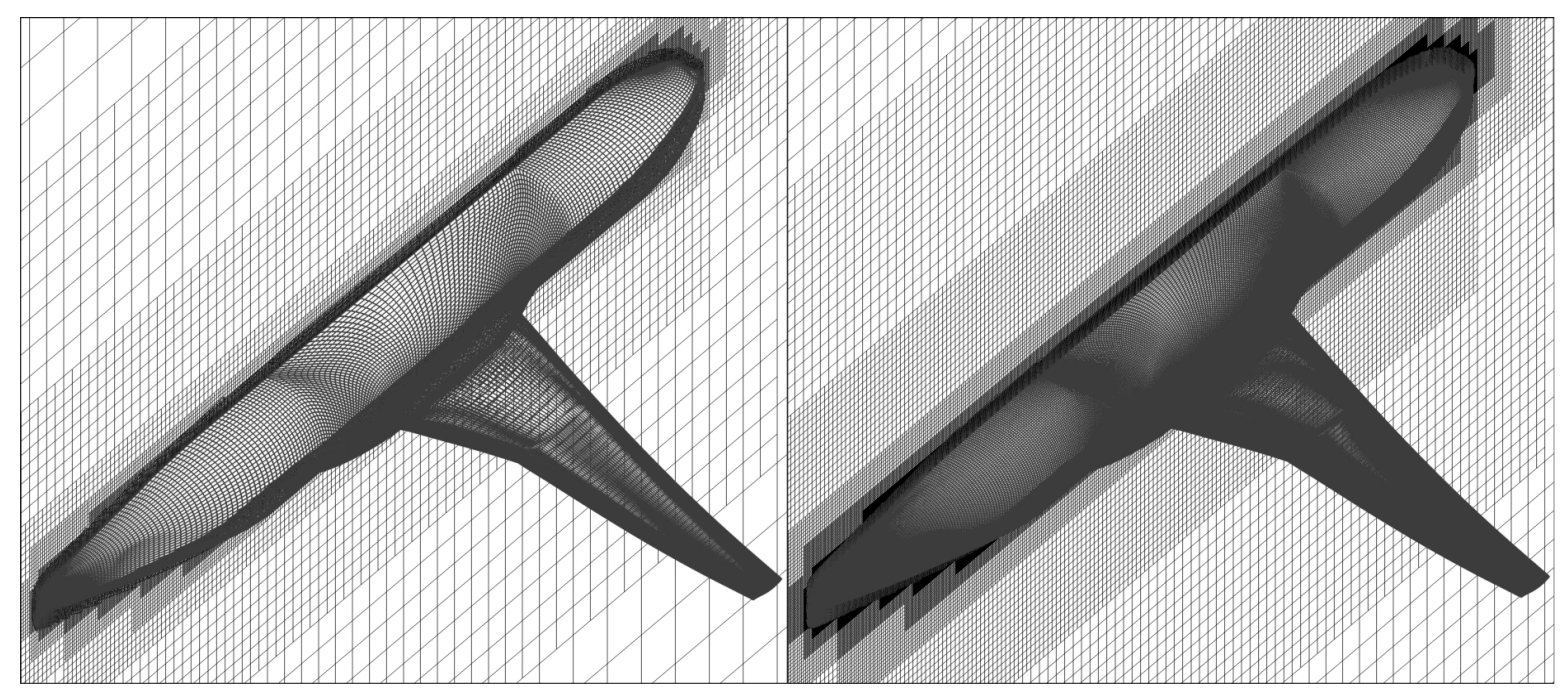

Fig. 20 Refinement levels of DO1 and DO2.

\section{Solver and Far-Field Post-Processing}

\section{A. ONERA - elsA Solver}

Structured RANS computations were performed with the ONERA-elsA Navier-Stokes solver [14]. This software uses a cell-centered Finite-Volume discretization on structured point-matched and overset meshes. Time integration is carried out by a backward-Euler scheme with implicit LU-SSOR relaxation. Spatial discretization is achieved 
using a $2^{\text {nd }}$ order centered scheme of Jameson et al. [32]. Multigrid techniques are used to accelerate the convergence. In this study, turbulence effects are simulated by the one-equation Spalart-Allmaras model [33].

All the $e l s A$ simulations were executed on a Silicon Graphics cluster (SGI ICE 8200). The overset computations carried out for this work have been performed in distributed mode, using 48 cores.

\section{B. ONERA - ffd72 Post-Processing Code: the Far-Field Approach}

The far-field method consists in integrating values in the flow domain whereas the near-field approach uses skin integrations only. The formulations and methods relative to the far-field theory have been presented in former publications $[24,34,35,36]$. In this study, all the far-field analyses are carried out with the drag extraction software $f f d 72$. It is entirely based on the formulations given in these references.

This code was developed to provide a physical drag breakdown into viscous, wave, and lift-induced components and therefore to eliminate the spurious drag by difference with the near-field drag coefficient. In practice, different volumes are defined around the aircraft so that the drag productions can be integrated (see Fig. 21). The control volumes $\mathrm{Vv}$ and $\mathrm{Vw}$, respectively used to calculate the viscous and wave drag components, are defined automatically with physical criteria. They encapsulate the viscous layers (boundary layer and wake) and shocks. Then, the volume which is considered for the lift-induced drag integration is specified by geometric constraints as shown in [24].

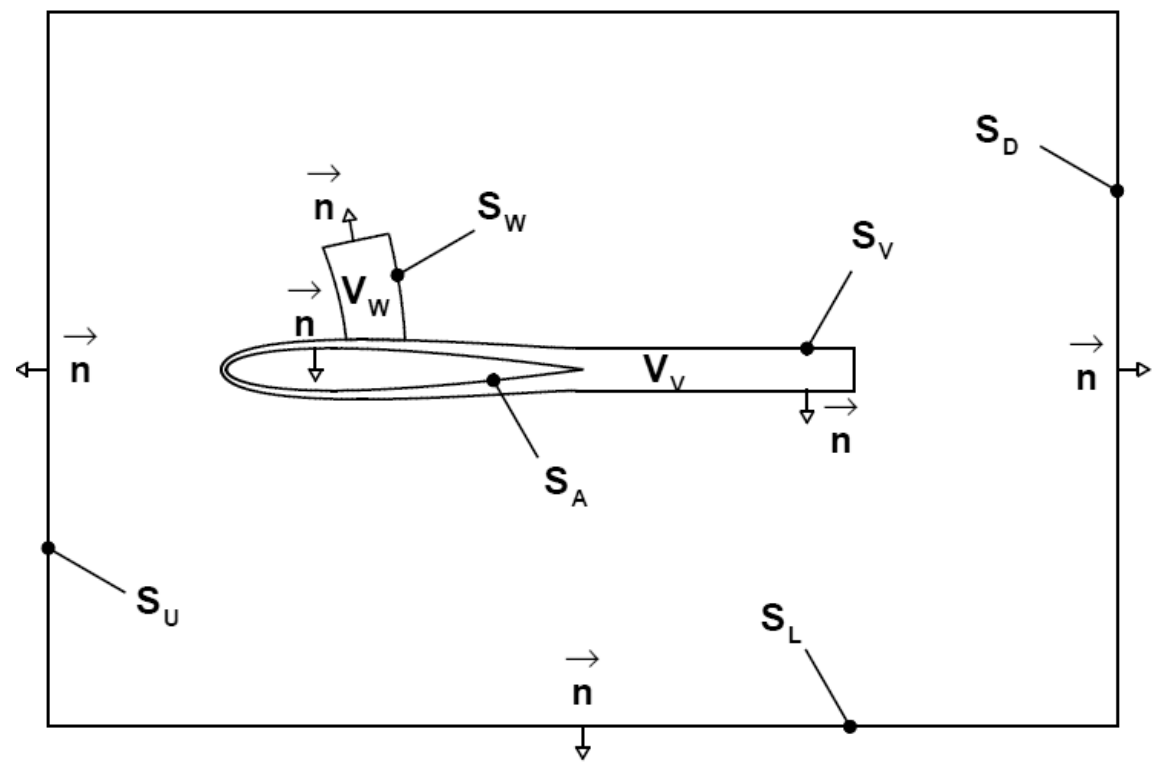

Fig. 21 Control surfaces and volumes for far-field drag integration. 
With its capability of quantifying the spurious drag, $f f d 72$ is perfectly suitable for evaluating the quality of a mesh. Indeed, a mesh of poor quality will inevitably exhibit a strong spurious drag. By extension, this tool is a precious ally in order to validate a meshing strategy. $f f d 72$ is used at the end of the CFD process. It is a postprocessing code working on the numerical solutions provided by the solver. The different drag coefficients which are used in this article are defined here:

$$
\begin{gathered}
C D_{n f}=C D_{p}+C D_{f} \text { (1) } \\
C D_{f f}=C D_{v}+C D_{w}+C D_{i} \text { (2) } \\
C D_{s p}=C D_{n f}-C D_{f f}(\mathbf{3})
\end{gathered}
$$

While the first equation represents the classical breakdown of the near-field drag into pressure and friction components (which requires surface integrations only), the second exhibits the far-field drag coefficients. The spurious drag is then defined as drag generated through entropy or stagnation enthalpy variations along streamlines outside physical viscous layers and shocks, and not resulting from vortex decay. It is generally produced in regions of strong pressure gradients via the addition of artificial dissipation.

Moreover, the viscous pressure drag CDvp is also defined. It is the part of the viscous drag which is not due to the friction drag (displacement effect, flow separation...):

$$
C D_{v}=C D_{v p}+C D_{f}(\mathbf{4})
$$

The far-field formulation allows for the following near-field/far-field drag balance:

$$
C D_{p}+C D_{f}=C D_{v}+C D_{w}+C D_{i}+C D_{s p}
$$


Fig. 22 shows some of the capabilities of the far-field code $f f d 72$. It gives the integration volumes of the viscous drag (around the plane boundary layer and wake) and of the wave drag (in black along the upper part of the wing) for the CRM configuration in cruise conditions. As explained, these volumes allow to calculate the far-field drag productions but moreover, they also enable to locate them around the aircraft. For a perfect understanding about the far-field integration volume features, see [24]. In Fig. 22, a specific point which can be noticed is that some Cartesian cells are inside the viscous volume (wing wake).

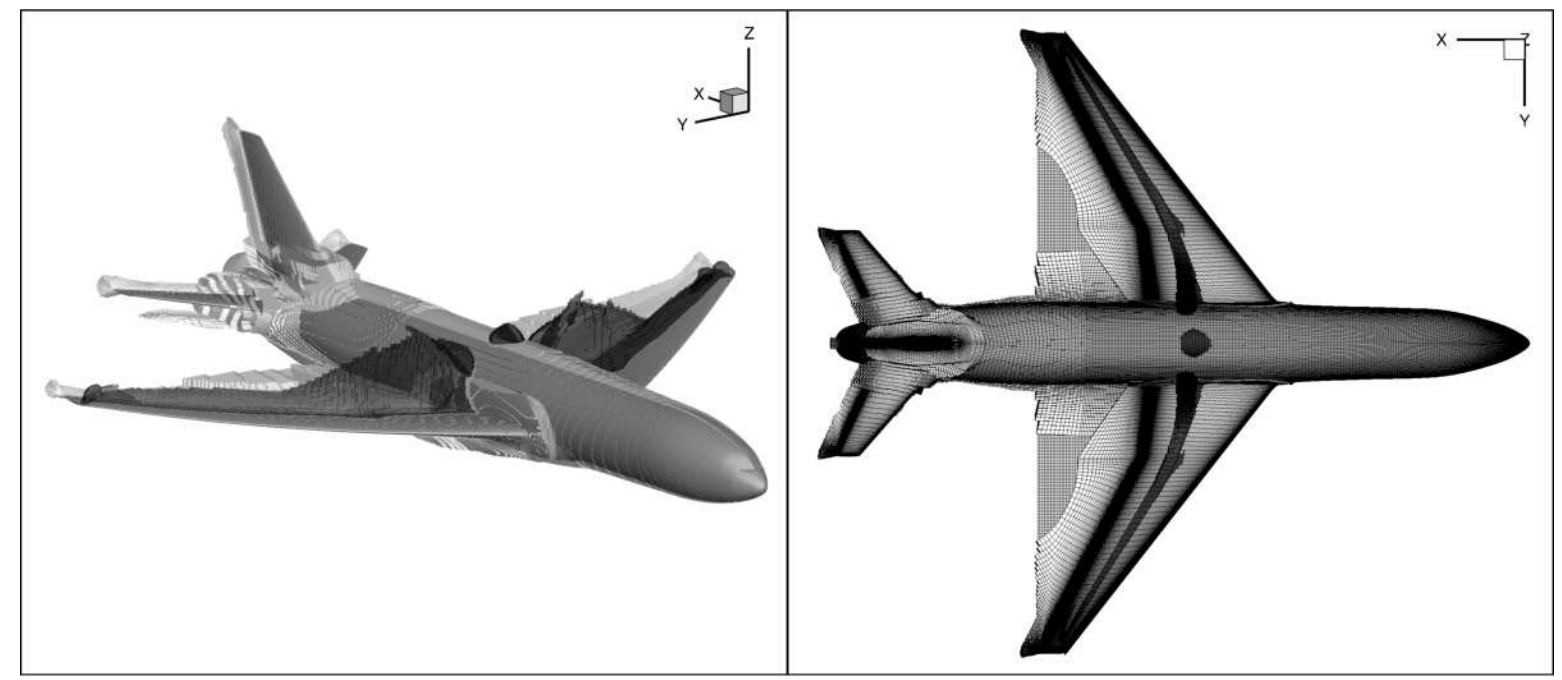

Fig. 22 WB-HTP-VTP $(\mathrm{O3}), M a=0.85, R e=5 \times 10^{6}, C L=0.5: f f d 72$ integration volumes. 


\section{Numerical Considerations and Results}

\section{A. General Numerical Considerations}

Before presenting the RANS computations which have been carried out, some points concerning the numerical convergence will be addressed. Indeed, several aspects can affect or improve the convergence process. First, the multigrid techniques can accelerate it. Nevertheless, the issue of multigrid methods applied on overset grids is known to be tricky (problems of blanking or interpolations on coarse grids). As a consequence, even if some tests have been done with two multigrid levels (i.e. two coarse levels generated from the initial mesh), the computations with only one multigrid level have been preferred. Then, as already said, the choice of blanking method (with or without overlap optimization) can have a significant impact on the computation convergence.

The tests which have been performed are summarized in Fig. 23. The first set of grids described above has been used $\left(\mathrm{Ol}_{0}, \mathrm{O} 1\right.$, and $\left.\mathrm{O} 2\right)$. It is important to underline that all the computations concerning the CRM WB configuration shown in Fig. 23 converge to almost identical drag coefficients at the design point. As it can be observed, the multigrid method (even with only one level) significantly improves the convergence behavior. On the other hand, the time needed here for one solver iteration is nearly doubled using one multigrid level in comparison with a computation with no multigrid acceleration technique.

What is remarkable in Fig. 23 is the fact that the overlap optimization dramatically accelerates the convergence in this case. Despite this step can be long, it seems quite relevant, especially if many calculations are to be done. The number of computed cells is slightly lower using the overlap optimization, but this does not improve the time required to perform one iteration, since blanked regions are not removed from the global mesh. Then, it can be noticed that adding elements (such as the HTP) does not affect the good convergence which is observed. 


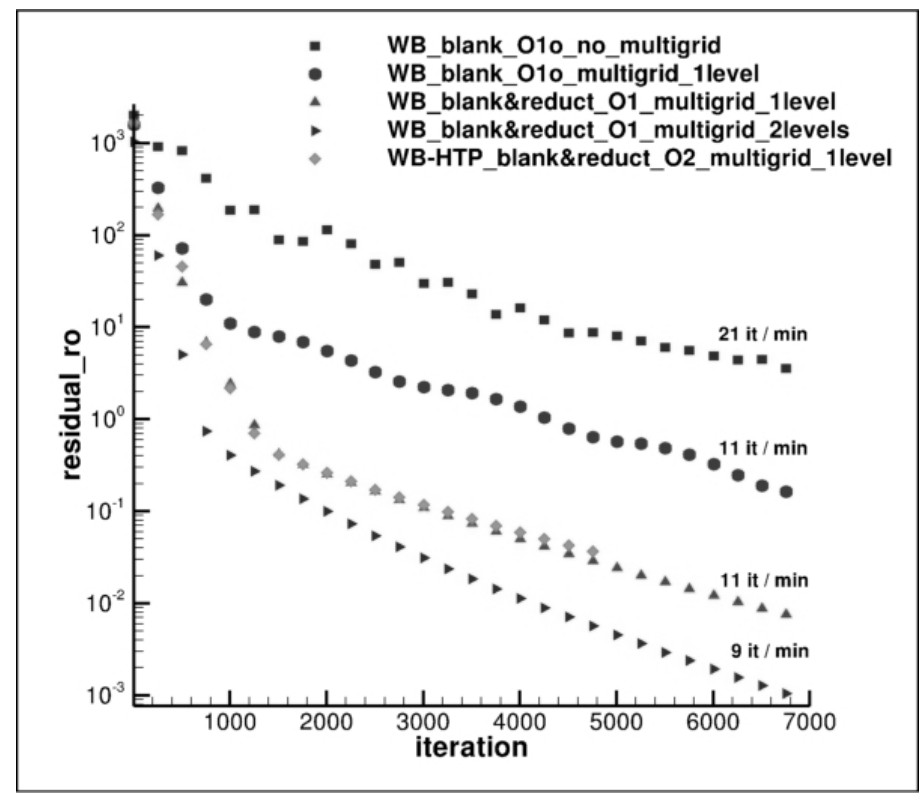

Fig. 23 Numerical convergence behaviors at the design point.

To conclude, in order to reach a satisfactory level of convergence, the iterations were continued largely after the fluxes were stable enough to observe a lift variation inferior to +/- 0.001 and a drag variation inferior to one count as it is displayed in Fig. 24 for the WB-HTP with blanking and overlap optimization (O2) using one multigrid level.

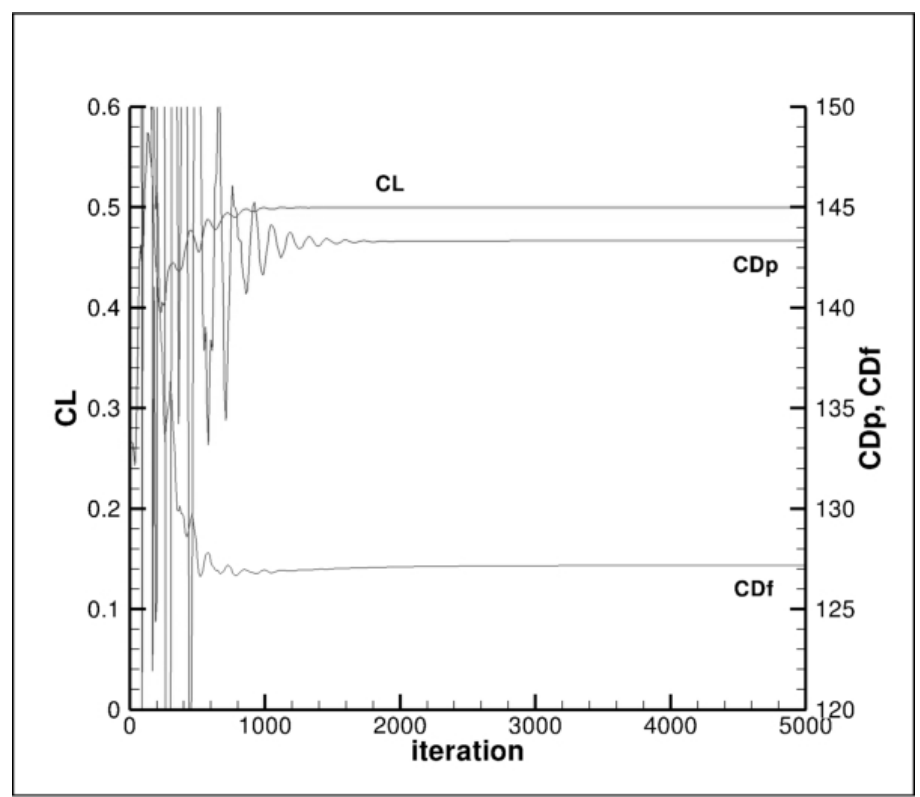

Fig. 24 WB-HTP (O2): convergence of the fluxes at the design point. 


\section{B. 1st Set of Computations}

The results given in this section correspond to the ONERA overset grids presented in Table 2. First, comparisons involving the global aerodynamic coefficients will be carried out. In a second time, some local analyses will be shown.

\section{Global Analyses}

This part starts with the results obtained with the Wing-Body configuration. As a consequence, the first computations which are presented have been carried out using $\mathrm{O} 1 \mathrm{o}$ and $\mathrm{O} 1$ grids. Their size is similar to the size of the L4 mesh of the common DPW-5 mesh family. Therefore, it will logically be used for validation purposes. Furthermore, to make the comparisons more complete, the values obtained with the finest mesh of the $\mathrm{L}_{\mathrm{i}}$ family will be added. L4 and L6 results are directly extracted from reference [25]. Both mesh groups $\left(\mathrm{O}_{\mathrm{i}}\right.$ and $\left.\mathrm{L}_{\mathrm{i}}\right)$ have been treated with the same solver settings: Spalart-Allmaras turbulence model, Jameson scheme with same artificial dissipation, one multigrid level...

Table $4 \mathrm{WB}$ configuration, $M a=0.85, R e=5$ millions, $C L=0.5$, els $A$ and $f f d 72$ results

\begin{tabular}{|c|c|c|c|c|}
\hline & $O 1_{0}$ & 01 & L4 & L6 \\
\hline $\operatorname{Alpha}\left({ }^{\circ}\right)$ & 2.129 & 2.121 & 2.153 & 2.153 \\
\hline$C D n f$ & 250.3 & 250.1 & 249.8 & 249.7 \\
\hline$C D p$ & 135.2 & 135.1 & 135.1 & 134.7 \\
\hline$C D f$ & 115.1 & 115.0 & 114.7 & 115.0 \\
\hline$C D v p$ & 40.8 & 40.7 & 40.7 & 40.2 \\
\hline$C D v$ & 155.9 & 155.7 & 155.4 & 155.2 \\
\hline$C D w$ & 3.5 & 3.5 & 3.7 & 3.9 \\
\hline$C D i$ & 90.3 & 90.4 & 90.4 & 90.6 \\
\hline$C D f f$ & 249.7 & 249.6 & 249.4 & 249.7 \\
\hline$C D s p$ & 0.6 & 0.5 & 0.4 & 0.0 \\
\hline
\end{tabular}

Table 4 exhibits the solver and far-field post-processing outcomes at the design point: $M a=0.85, R e=5$ millions, $C L=0.5$. The following comments can be made:

1) Before focusing on the mesh comparisons, it can be observed that the aerodynamic coefficients obtained for the CRM WB are typical of today's commercial aircraft. The total drag is close to 250 counts: $54 \%$ of pressure drag and $46 \%$ of friction drag. The viscous drag alone represents $62 \%$ of total drag. On the other hand, the CRM wing 
exhibits a very low wave drag level (less than $2 \%$ ). The lift-induced drag component is close to $36 \%$ of the overall value which is an expected proportion for this type of aircraft in transonic conditions.

2) The last two columns of Table 4 confirm that the L4 mesh is fine enough to achieve a satisfactory accuracy. Indeed, the differences observed between L4 (17 million cells) and L6 (138 million cells) for each coefficient are below 0.5 drag count. As a consequence, the size of the grids $\mathrm{O}_{\mathrm{o}}$ and $\mathrm{O} 1$ should be large enough to obtain equivalent results.

3) Considering numerical aspects, it can be noticed that all the meshes shown in Table 4 produce very low levels of spurious drag. As this coefficient is a good indicator of the mesh quality, this fact is a first validation point for the grids $\mathrm{O}_{\mathrm{o}}$ and $\mathrm{O} 1$.

4) Focusing now on the values obtained with $\mathrm{O}_{\mathrm{o}}$ and $\mathrm{O} 1$, it can be seen that both blanking methods finally give very similar results in this case. Indeed, the aerodynamic coefficients of the first two columns are almost identical. Besides, the agreement which is observed with the $\mathrm{L}_{\mathrm{i}}$ family is very satisfactory: the differences observed for each component are clearly below the drag count.

5) Even if the agreement between the $\mathrm{O}_{\mathrm{i}}$ and $\mathrm{L}_{\mathrm{i}}$ grids is remarkable, a small difference appears concerning the $C D v$ and $C D w$ coefficients. Indeed, it seems that the ONERA grids predict a lower wave drag while the viscous drag is slightly stronger. Nevertheless, the amplitude of this transfer is so limited (less than 0.5 counts) that it might be impossible to determine which outcome should be preferred.

6) Finally, in order to add experimental data to this validation process, it is recalled that the NTF drag value for the CRM WB configuration at the design point is 248 points [29]. As a consequence, the drag prediction close to 250 counts obtained with the grids $\mathrm{O} 1_{\mathrm{o}}$ and $\mathrm{O} 1$ could be considered as satisfactory. Nevertheless, this agreement between numerical and experimental sources hides the fact that at least two phenomena compensate each other. First, as mentioned previously, the wing twist of the experimental model was different from the one of the numerical geometry: considering the wind tunnel twist implies a cost of 4 drag counts (50/50 contribution of lift-induced and wave components). Then, in the experiments, the wing flow was laminar up to $10 \%$ chord which represents a drag reduction of about 6 counts. Besides, support system effects are not taken into account. More detail about CRM WB numerical and experimental comparisons is available in [26]. 
As it has been shown that the ONERA grids of the Wing-Body configuration produce satisfactory results, the meshes including the horizontal tailplane can now be evaluated. In Table 5, the $\mathrm{O} 2$ mesh of the WB-HTP model is compared to the $\mathrm{O} 1$ mesh. The drag variation due to the HTP is therefore evaluated. The delta which was observed in DPW-4 studies [24] is recalled in the last column.

Table 5 HTP, $M a=0.85, R e=5$ millions, $C L=0.5$, elsA and $f f d 72$ results

\begin{tabular}{|c|c|c|c|c|}
\hline & O2 & O1 & $\begin{array}{c}\Delta \text { HTP with } \\
\text { ONERA grids }\end{array}$ & $\begin{array}{c}\Delta \text { HTP from } \\
\text { DPW4 }\end{array}$ \\
\hline $\boldsymbol{A l p h a}\left(^{\circ}\right)$ & 2.280 & 2.121 & 0.16 & 0.13 \\
\hline $\boldsymbol{C D n \boldsymbol { f }}$ & 270.5 & 250.1 & 20.4 & 19.7 \\
\hline $\boldsymbol{C D p}$ & 143.3 & 135.1 & 8.2 & 7.3 \\
\hline $\boldsymbol{C D} \boldsymbol{f}$ & 127.2 & 115.0 & 12.2 & 12.3 \\
\hline $\boldsymbol{C D} \boldsymbol{v} \boldsymbol{p}$ & 46.4 & 40.7 & 5.7 & 5.0 \\
\hline $\boldsymbol{C D} \boldsymbol{v}$ & 173.5 & 155.7 & 17.8 & 17.3 \\
\hline $\boldsymbol{C D} \boldsymbol{w}$ & 5.6 & 3.5 & 2.1 & 2.1 \\
\hline $\boldsymbol{C D} \boldsymbol{i}$ & 90.9 & 90.4 & 0.5 & 0.3 \\
\hline $\boldsymbol{C D} \boldsymbol{f f}$ & 270.1 & 249.6 & 20.5 & 19.6 \\
\hline $\boldsymbol{C D} \boldsymbol{p} \boldsymbol{p}$ & 0.4 & 0.5 & -0.1 & 0.1 \\
\hline
\end{tabular}

Concerning Table 5, it can be said that:

1) Due to the fact that the HTP produces a negative lift, the incidence which is necessary to reach $C L=0.5$ is increased. This has a negative impact on drag production. The total drag with HTP exhibits a value close to 270 counts. A great part of this additional drag is due to the friction component which is directly related to the wetted area. Over 20 counts of penalty, the friction drag represents a $60 \%$ contribution. Concerning pressure drag, the viscous pressure coefficient is increased of 5.7 counts $(28 \%)$ and the wave drag is submitted to a significant growth of 2.1 counts $(10 \%)$. As expected, the wave drag is very sensitive to the wing loading. Moreover, the fact that the spurious level remains almost identical signifies that the addition of the HTP mesh does not deteriorate the whole mesh quality.

2) When the delta due to the HTP of ONERA grids is compared to the values given by the DPW-4 meshes, it can be observed that the agreement is very good. The differences coefficient by coefficient are below the drag count. This can be considered as a quite satisfactory validation since the meshing approaches are completely different. Indeed, for the DPW-4 common studies, the computations were carried out with point-matched C-type grids of about 11 million cells and generating at least one count of spurious drag. 
3) Concerning wind tunnel data (NTF), the drag difference measured between the run 197-44 (WB) and the run 197-97 $\left(\mathrm{WB}^{-\mathrm{HTP}^{\circ}}\right)^{\circ}$ is close to 21 counts. Therefore, the experimental and numerical drag variations due to the addition of the HTP exhibit a very good agreement.

To conclude on the global comparisons of ONERA and DPW grids, it has been shown that the near-body/offbody mesh partitioning is perfectly suitable for producing very satisfactory results in agreement with the today's CFD accuracy standards.

As specified previously, even if no other data exists concerning the vertical tailplane, the results which have been achieved with the full CRM configuration will be presented. In Table 6, the values corresponding to the O3 mesh are compared to the WB-HTP configuration. Consequently, the delta due to the VTP can be quantified. As it can be noticed, the total drag penalty reaches about 11 counts. This is mainly due to the friction drag increase $(77 \%)$. A simple verification can be done considering the wetted areas. The VTP planform is basically 1.5 times greater than the one of HTP (trapezium surface law). However, as only a half configuration is computed, the VTP surface is close to $75 \%$ of the HTP wetted area. Since the friction drag increase due to the HTP is close to 12 counts, the expected friction drag cost coming from the VTP should be close to 9 counts. As it can be noticed in Table 6 , this is verified. Furthermore, the obstruction caused by the VTP implies that the negative lift level generated by the HTP is weaker. As a consequence, the incidence at $C L=0.5$ is $0.045^{\circ}$ lower with the $\mathrm{O} 3$ mesh. It causes non-negligible reductions of the wave and lift-induced drag coefficients. These outcomes will have to be compared to the future ONERA wind tunnel tests involving the CRM vertical tailplane.

Table $6 \mathrm{VTP}, M a=0.85, \operatorname{Re}=5$ millions, $C L=0.5$, $e l s A$ and $f f d 72$ results

\begin{tabular}{|c|c|c|c|}
\hline & $\mathbf{O 3}$ & $\mathbf{O 2}$ & $\begin{array}{c}\Delta \text { VTP with } \\
\text { ONERA grids }\end{array}$ \\
\hline $\boldsymbol{A l p h a}\left(^{\circ}\right)$ & 2.235 & 2.280 & -0.045 \\
\hline $\boldsymbol{C D n f}$ & 281.6 & 270.5 & 11.1 \\
\hline $\boldsymbol{C D p}$ & 145.7 & 143.3 & 2.4 \\
\hline $\boldsymbol{C D f}$ & 135.8 & 127.2 & 8.6 \\
\hline $\boldsymbol{C D} \boldsymbol{v} \boldsymbol{p}$ & 50.0 & 46.4 & 3.6 \\
\hline $\boldsymbol{C D} \boldsymbol{v}$ & 185.8 & 173.5 & 12.3 \\
\hline $\boldsymbol{C D} \boldsymbol{w}$ & 4.8 & 5.6 & -0.8 \\
\hline $\boldsymbol{C D i}$ & 90.5 & 90.9 & -0.4 \\
\hline $\boldsymbol{C D f f}$ & 281.1 & 270.1 & 11.0 \\
\hline $\boldsymbol{C D} \boldsymbol{p} \boldsymbol{p}$ & 0.5 & 0.4 & 0.1 \\
\hline
\end{tabular}




\section{Local Insights}

As it has been announced, in addition to the global comparisons, local analyses confronting ONERA and DPW grids will be presented.

The first aspect which will be addressed is the side-of-body flow separation prediction. As mentioned in paragraph IV-B, the $\mathrm{O}_{i}$ and $\mathrm{L}_{\mathrm{i}}$ families have different topologies at the wing-body junction (see Fig. 3 and Fig. 5). As it can be observed in Fig. 25, the ONERA $\mathrm{O} 1$ mesh is much more refined in the spanwise and normal directions than the L4 mesh. As a consequence, the flow resolution in this area cannot be similar. Besides, even when only the $\mathrm{L}_{\mathrm{i}}$ family is considered, it has been demonstrated that the flow separation increases with the mesh resolution (with the standard Spalart-Allmaras model, see [25]). As it can be noticed in Fig. 26, the topology of ONERA overset grids at the root is clearly favorable for the appearance of larger flow separations. Nevertheless, as shown in Table 4, the impact of this greater side-of-body separation remains negligible in terms of global drag coefficients. Furthermore, some tests have shown that the use of QCR corrections [37] leads to smaller corner flow separations even in presence of fine meshes.

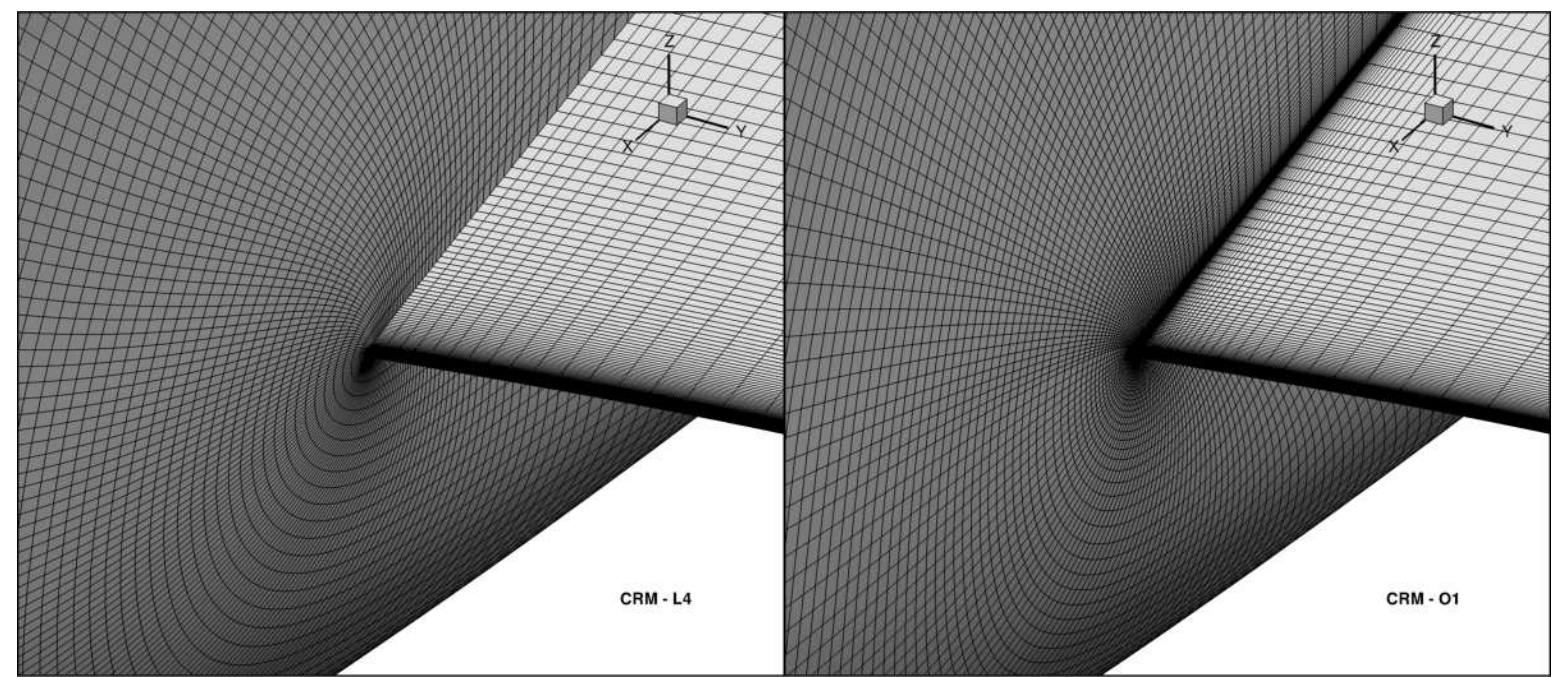

Fig. 25 Mesh topologies of L4 and 01 at the wing-body junction trailing edge. 


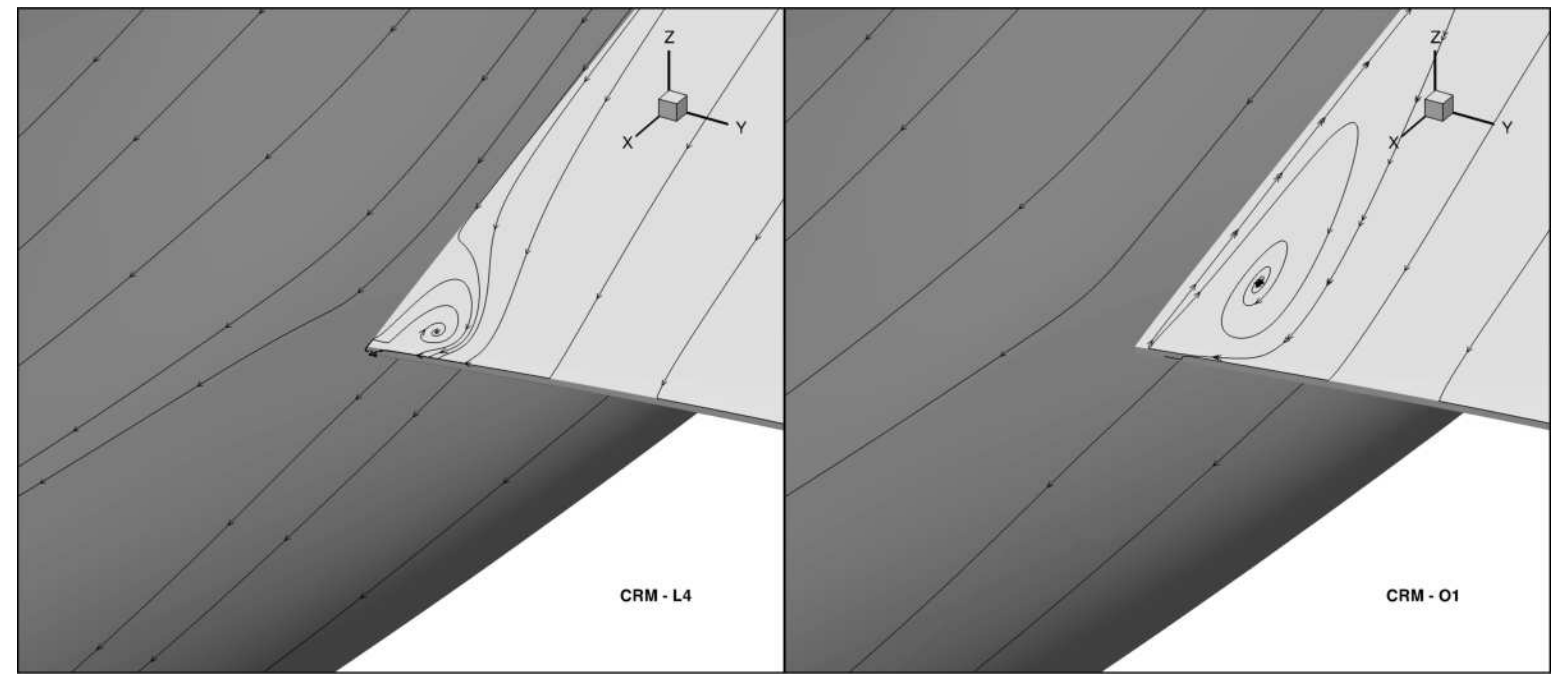

Fig. 26 Side-of-body flow separations obtained with the grids L4 and $\mathrm{O1}$ at the design point.

Then, still focusing on the WB configuration, the pressure distributions have been investigated. The values obtained with the L4 and O1 meshes at 50 and 95\% of wingspan are given in Fig. 27. It can be observed that the agreement is very good at midspan. On the other hand, at 95\% span, some small discrepancies are visible on the first part of the upper side. Nevertheless, these differences are very limited in amplitude. In [26], it can be seen that the difference of wing twist values between the experimental and numerical models reveals much more significant discrepancies on pressure distributions at wingtip than what is shown in Fig. 27. This area of the wing is known to be very sensitive. As a conclusion on pressure distributions, the agreement between the ONERA overset meshes and the common DPW family of meshes is satisfactory.

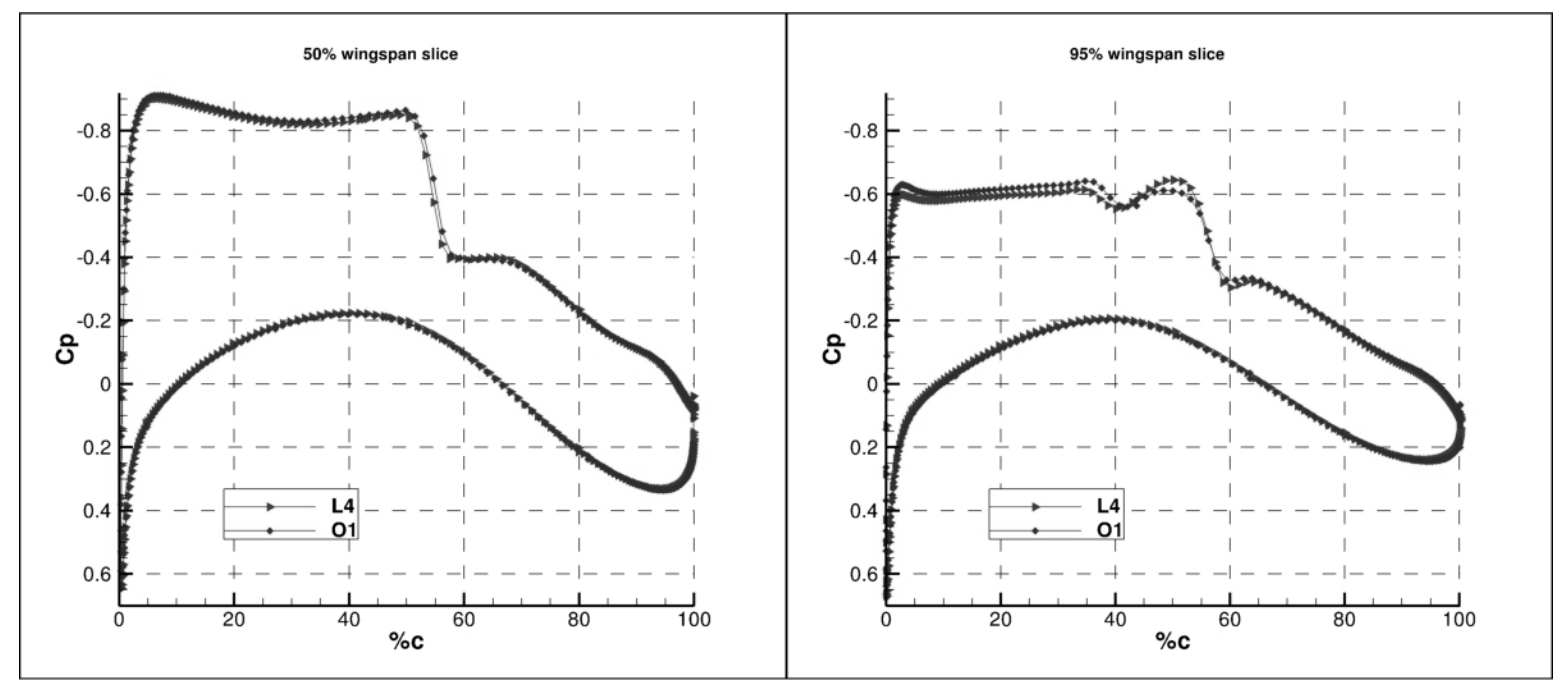

Fig. 27 Numerical $C p$ distributions obtained with the grids $L 4$ and $O 1$ at the design point. 
To conclude this section, some far-field local analyses are presented. The productions of the viscous pressure and wave components in the spanwise direction are shown in Fig. 28. The results obtained with the O1 mesh are compared to the values of the L4 mesh extracted from [26]. As in Table 4, it can be seen that both meshes produce almost the same outcomes. In order to add a comparison point, which allows to show that the discrepancies between L4 and $\mathrm{O} 1$ are very limited, the spanwise productions given by the $\mathrm{O} 3$ mesh are also visible. Since this configuration includes the horizontal and vertical tailplanes, the profiles concerning O3 are significantly different. Due to the HTP position, the viscous pressure production in the first $30 \%$ of the span is much greater than it is for the WB geometry. Considering the wave drag production, the fact that the coefficient obtained with the O3 mesh (4.8 counts) is stronger than the one given by $\mathrm{O} 1$ mesh $(3.5$ counts) is clearly explained by Fig. 28 . For the latter, the shock produces lower drag in the middle part of the wing.

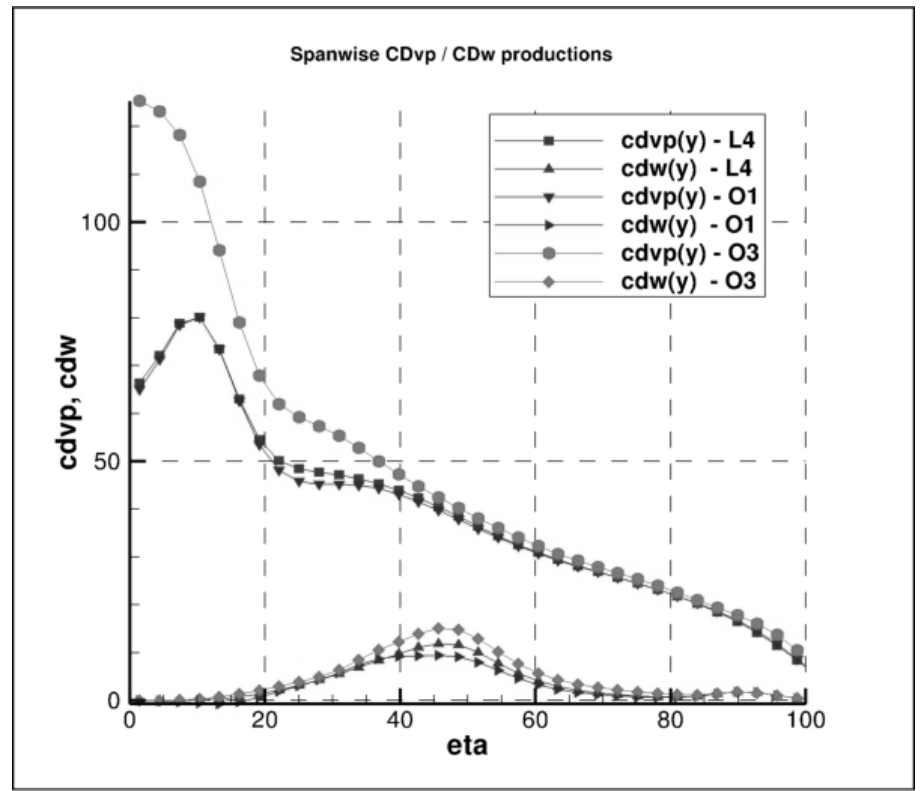

Fig. $28 C D v p$ and $C D w$ spanwise productions obtained with L4, O1, and 03 meshes at the design point.

\section{2nd Set of Computations}

The results shown in this section correspond to the mixed DPW-ONERA grids of the WB configuration presented in Table 3. The objective here is to evaluate the influence of the off-body Cartesian mesh adaptation, when near-body grids extend to a distance that is too short downstream of the wing. The chosen sensor field for this 
adaptation is the turbulent viscosity. Initially, the Cartesian off-body mesh is refined in the vicinity of the bodies only, and not in the wake of the wing. After a first computation performed with the initial mesh, the Cartesian grid is adapted according to the octree approach described in [8]. The converged previous solution is projected onto the adapted mesh, and the computation is restarted.

Fig. 29 illustrates the result of one adaptation applied on the coarsest grid of the $\mathrm{DO}_{\mathrm{i}}$ family. As it can be observed with the DO1 mesh, the wing wake is strongly dissipated when crossing coarser Cartesian cells. On the other hand, the wake resolution is much more satisfactory with the DO2 mesh. However, as indicated in Table 3 , this better resolution implies a mesh size which can be prohibitive. The mesh $\mathrm{DO} 1_{\mathrm{a}}$ exhibits a good compromise: limited cost in term of grid size but a wake resolution almost as satisfactory as the one of the largest mesh. As it can be noticed, the adaptation algorithm has imposed a better refinement rightly located in the wake area. As a consequence, in this zone, the refinements of $\mathrm{DO}_{\mathrm{a}}$ and $\mathrm{DO} 2$ are equivalent.
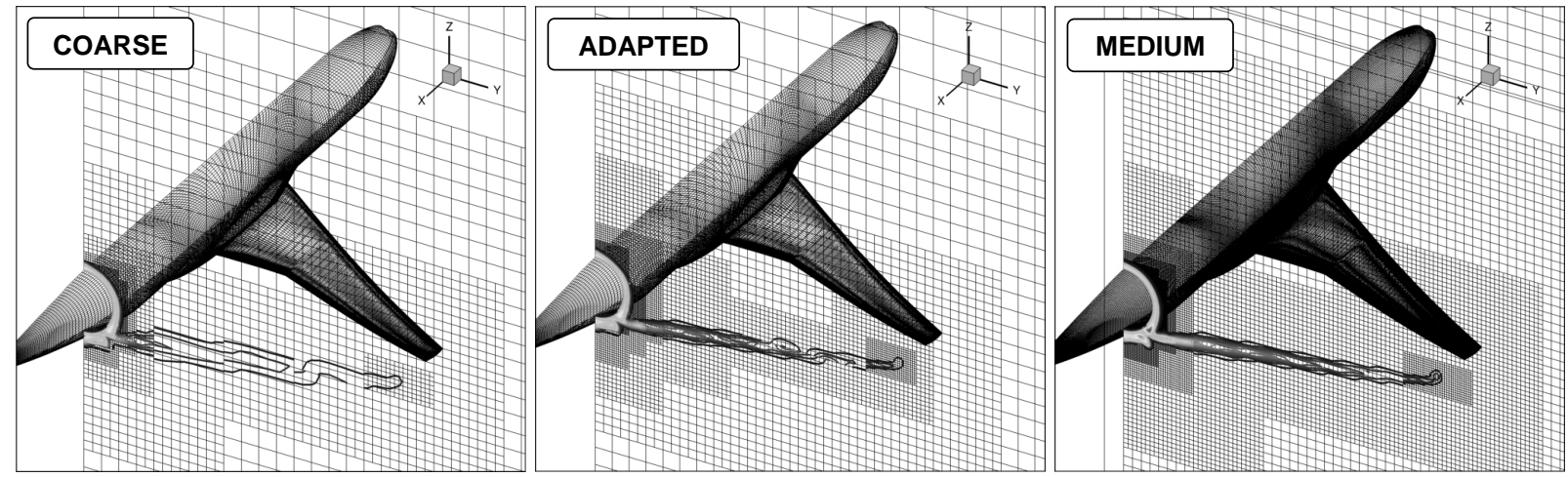

Fig. 29 Flow resolution in the wake of $\mathrm{DO1}$, $\mathrm{DO1}_{\mathrm{a}}$, and $\mathrm{DO} 2$ wings.

In order to evaluate the impact of such an adaptation on the global drag coefficients, Table 7 summarizes the results obtained with the $\mathrm{DO}_{\mathrm{i}}$ family. L2 and L4 meshes are also presented as their near-body grids have been used to generate the mixed DPW-ONERA grids. It can be observed that the results given by the coarse DO1 mesh are quite satisfactory compared to the results obtained with the L2 mesh. Nevertheless, there is an unexpected transfer from the lift-induced drag to the viscous pressure component. This small anomaly disappears with the DO2 mesh. The latter produces results which are in good agreement with the reference L4: the discrepancies between far-field coefficients are below the drag count. Considering the adapted $\mathrm{DO} 1_{\mathrm{a}}$ mesh, the values displayed in Table 7 allow to 
state that the adaptation has helped improving the accuracy of drag prediction. Indeed, the drag levels obtained with $\mathrm{DO}_{\mathrm{a}}$ are clearly between the outcomes of DO1 and DO2. The lift-induced and viscous pressure drag predictions are more accurate with $\mathrm{DO}_{\mathrm{a}}$ than with DO1. As a conclusion, the Cartesian mesh adaptation based on turbulent viscosity has led to a better resolution of the wing wake without deteriorating the accuracy of the drag prediction.

Table 7 DPW-ONERA grids, $M a=0.85, R e=5$ millions, $C L=0.5$, els $A$ and $f f d 72$ results

\begin{tabular}{|c|c|c|c|c|c|}
\hline & DO1 & DO1 $_{\mathbf{a}}$ & L2 & DO2 & L4 \\
\hline $\boldsymbol{A l p h a}\left(^{\circ}\right)$ & 2.170 & 2.170 & 2.181 & 2.150 & 2.153 \\
\hline $\boldsymbol{C D n f}$ & 252.1 & 250.7 & 253.0 & 251.4 & 249.8 \\
\hline $\boldsymbol{C D} \boldsymbol{p}$ & 137.8 & 136.4 & 139.1 & 136.6 & 135.1 \\
\hline $\boldsymbol{C D} \boldsymbol{f}$ & 114.3 & 114.3 & 113.9 & 114.8 & 114.7 \\
\hline $\boldsymbol{C D} \boldsymbol{p} \boldsymbol{}$ & 43.9 & 42.0 & 42.7 & 41.1 & 40.7 \\
\hline $\boldsymbol{C D} \boldsymbol{v}$ & 158.2 & 156.3 & 156.6 & 155.9 & 155.4 \\
\hline $\boldsymbol{C D} \boldsymbol{w}$ & 4.0 & 4.0 & 3.9 & 3.5 & 3.7 \\
\hline $\boldsymbol{C D} \boldsymbol{i}$ & 88.8 & 89.5 & 90.09 & 90.9 & 90.4 \\
\hline $\boldsymbol{C D} \boldsymbol{f} \boldsymbol{C D} \boldsymbol{p}$ & 251.0 & 249.8 & 251.4 & 250.3 & 249.4 \\
\hline & 1.1 & 0.9 & 1.6 & 1.1 & 0.4 \\
\hline
\end{tabular}

\section{Conclusions}

This article is focused on a methodology relying on the partitioning of the computational domain into near-body and off-body regions. Off-body regions are meshed by Cartesian grids that can be adapted according to flow features, whereas near-body grids are defined around each element of the configuration. The objective was to demonstrate that using this approach with ONERA modules and a relevant near-body mesh generation tool allows to complete the pre-processing of a quite complex CFD simulation within a few days, with good-quality results.

In order to validate this approach, the well-known NASA Common Research Model has been chosen. Furthermore, in the idea of highlighting the flexibility of the approach, the vertical tailplane designed at ONERA for the CRM has been used as an additional overset element. Still for validation purposes, both numerical and experimental data have been considered. The numerical data which has been employed is based on the great amount of results obtained in the context of DPW-4 and DPW-5. In particular, an intensive use of the common pointmatched multiblock mesh family provided by the DPW-5 Committee has been done. The wind tunnel measurements which have been used are from the National Transonic Facility. 
The meshing method has been precisely described. Its advantages have been highlighted: easiness, flexibility, rapid implementation, Cartesian grid adaptation. Each step has been explained in detail: creation of near-body grids with commercial meshing software, Cartesian grid generation, and overset assembly with the in-house Cassiopée modules. Guidelines have been proposed. Then, the two sets of overset grids used in this study have been presented. The first one corresponds to ONERA grids created from zero. The following configurations have been addressed: Wing-Body, Wing-Body with HTP, and Wing-Body with HTP and VTP. The second set is made of mixed DPWONERA grids for which Cartesian mesh adaptations have been performed.

Once the ONERA elsA solver and far-field post-processing code $f f d 72$ have been described, some numerical considerations concerning especially the topic of convergence were discussed. Then, the results obtained with the first set of grids have been given. The global near-field and far-field drag coefficients have been presented for all the geometries mentioned above: the agreement which has been observed between the grids generated following the ONERA meshing approach and the common DPW meshes is remarkable. On the WB configuration for instance, the differences for each drag component are clearly below the count. The delta in drag due to the HTP obtained with the ONERA overset grids has been confirmed by DPW-4 grids and NTF data. Concerning local analyses, since the topology of ONERA grids leads to very strong refinements close to the element junctions, the side-of-body flow separations can be slightly larger. On the other hand, a good agreement is observed for pressure distributions and local drag productions. Considering the second set of grids and results, it has been shown that the Cartesian mesh adaptation based on turbulent viscosity enables a better resolution of the wakes without deteriorating the drag prediction.

Today, this approach is more and more used at ONERA. It has already been applied to more complex aircraft configurations than the CRM and has allowed to obtain very accurate performance predictions.

\section{Acknowledgments}

The authors would like to thank ONERA - the French Aerospace Lab for the funding of this research. The authors also thank the DPW Organizing Committee and finally all the people who have contributed to the development of the meshing strategy which is presented in this article. 


\section{References}

1. Steger, J.L., Dougherty, F.C. and Benek, J.A., “A Chimera Grid Scheme,” Advances in Grid Generation, Vol. 5, pp. 5969, 1983.

2. Henshaw, W.D., "OVERTURE: an object-oriented framework for overlapping grid applications," AIAA paper 20023189, 2002.

3. Chan, W.M., "Overset grid technology development at NASA Ames Research Center," Computers \& Fluids, Vol. 38, pp. 496-503, 2009.

4. Lee, H. C., and Pulliam, T. H., "Effect of Using Near and Off-body Grids with Grid Adaptation to Simulate Airplane Geometries,” AIAA Paper 2011-3985, 2011.

5. Buning, P. G., and Pulliam, T. H., "Cartesian Off-Body Grid Adaptation for Viscous Time-Accurate Flow Simulation," AIAA Paper 2011-3693, 2011.

6. Meakin, R.L., "An efficient means of adaptive refinement within systems of overset grids," AIAA paper 95-1722-CP, 1995.

7. Meakin, R.L., “Adaptive Spatial Partitioning and Refinement for Overset Structured Grid," Computer Methods in Applied Mechanics and Engineering, Vol. 189 (4), pp. 1077-1117, 2000.

8. Péron, S., and Benoit, C., "Automatic off-body overset adaptive Cartesian mesh method based on an octree approach," Journal of Computational Physics, vol. 232 (1), pp. 153-173, 2013.

9. Péron, S., Benoit, C., Landier, S., and Raud, P., "Cassiopée: CFD Advanced Set of Services In an Open Python EnvironmEnt," $12^{\text {th }}$ Symposium on Overset Grid and Solution Technology, Atlanta, 2014.

10. Suhs, N.E., Rogers, S.E., and Dietz, W.E., "PEGASUS5: an automated pre-processor for Overset-grid CFD," AIAA paper 2002-3186, 2002.

11. Sitaraman, J., Floros, M., Wissink, A., and Potsdam, M., "Parallel domain connectivity algorithm for unsteady flow computations using overlapping and adaptive grids," Journal of Computational Physics, vol. 229, pp. 4703-4723, 2010.

12. Noack, R.W., "SUGGAR++: An Improved General Overset Grid Assembly Capability,” AIAA Paper 2009-3992, 2009.

13. Nichols, R.H., Tramel, R.W., and Buning, P.G., "Solver and Turbulence Model Upgrades to OVERFLOW 2 for Unsteady and High-Speed Applications,” AIAA paper 2006-2824, 2006.

14. Cambier, L., Heib, S., and Plot, S., "The ONERA elsA CFD Software: Input from Research and Feedback from Industry," Mechanics and Industry, Vol. 15(3), pp. 159-174, 2013. 

program," $31^{\text {st }}$ European Rotorcraft Forum, 2005.

16. "Mesh Generation Software for CFD - Pointwise," http://www.pointwise.com [retrieved July 2014].

17. Péron, S, "Méthode d'assemblage de maillages recouvrants autour de géometries complexes pour des simulations en aérodynamique compressible,” PhD Thesis, Arts \& Métiers ParisTech, 2014.

18. Péron, S., and Benoit, C. "Development of a Python Preprocessing Module for Chimera Assembly for CFD Applications," 10 Symposium on Overset Grids and Solution Technology, 2010.

19. Wiart, L., and Moens, F., "Numerical Simulation of the NASA High-Lift Trap Wing with the elsA CFD Software," AIAA Paper 2012-2918, 2012.

20. Renaud, T., Le Pape, A., and Péron, S., "Numerical analysis of hub and fuselage drag breakdown of a helicopter configuration,” CEAS Aeronautical Journal, vol. 4 (4), pp 409-419, 2013.

21. Boisard, R., et al, "Assessment of aeromechanics and acoustics methods for BVI prediction using CFD," $39^{\text {th }}$ European Rotorcraft Forum, 2013.

22. DPW-5 website, http://aaac.larc.nasa.gov/tsab/cfdlarc/aiaa-dpw/.

23. Vassberg, J. C., DeHann, M. A., Rivers, S. M., and Wahls, R. A., "Development of a Common Research Model for Applied CFD Validation Studies,” AIAA Paper 2008-6919, 2008.

24. Hue, D., and Esquieu, S., "Computational Drag Prediction of the DPW4 Configuration Using the Far-Field Approach" Journal of Aircraft, Vol. 48(5), pp. 1658-1670, 2011.

25. Hue, D., "Fifth Drag Prediction Workshop: Computational Fluid Dynamics Studies Carried Out at ONERA," Journal of Aircraft, vol. 51(4), pp. 1295-1310, 2014.

26. Hue, D., "Fifth Drag Prediction Workshop: ONERA Investigations with Experimental Wing Twist and Laminarity," Journal of Aircraft, vol.51(4), pp. 1311-1322, 2014.

27. Rivers, M. B., Hunter, C. A., and Campbell, R., L., "Further Investigation of the Support System Effects and Wing Twist on the NASA Common Research Model,” AIAA Paper 2012-3209, 2012.

28. Vassberg, J. C., "A Unified Baseline Grid about the Common Research Model Wing-Body for the Fifth AIAA CFD Drag Prediction Workshop,” AIAA Paper 2011-3508, 2011.

29. Rivers, M. B., and Dittberner, A., "Experimental Investigations of the NASA Common Research Model in the NASA Langley National Transonic Facility and NASA Ames 11-Ft Transonic Wind Tunnel,” AIAA Paper 2011-1126, 2011.

30. Levy, D. W., et al., "Summary of Data from the Fifth AIAA CFD Drag Prediction Workshop," AIAA Paper 2013-0046, 2013. 
31. Schwarz, Th., "An Interpolation Method maintaining the Wall Distance for Structured and Unstructured Overset Grids," CEAS 2009 European Air and Space Conference, 2009.

32. Jameson, A., Schmidt, W., and Turkel, E., "Numerical Solution of the Euler Equations by Finite Volume Methods Using Runge Kutta Time Stepping Schemes,” AIAA-81-1259, 1981.

33. Spalart, P. R., and Allmaras, S. R., "A One-Equation Turbulence Model for Aerodynamic Flows," AIAA Paper 92-0439, 1992.

34. Destarac, D., "Far-Field / Near-Field Drag Balance Applications of Drag Extraction in CFD," CFD-Based Aircraft Drag Prediction and Reduction, VKI Lecture Series 2003-02, von Karman Institute for Fluid Dynamics, Rhode-Saint-Genèse, Belgium, 2003.

35. Van der Vooren, J., and Destarac, D., “Drag / Thrust Analysis of Jet-propelled Transonic Transport Aircraft; Definition of Physical Drag Components," Aerospace Science and Technology, vol.8(6), pp. 545-556, 2004.

36. Destarac, D., "Drag Extraction from Numerical Solutions to the Equations of Fluid Dynamics: the Far-field Philosophy," $43^{\text {rd }}$ Applied Aerodynamics Conference of the Aeronautical and Astronautical French Association, 2008.

37. Spalart, P. R., "Strategies for Turbulence Modeling and Simulations," International Journal of Heat and Fluid Flow, Vol. 21, pp. 252-263, 2000. 